\title{
ANÁLISE PROSOPOGRÁFICA DOS DIRETORES DO BNDES
}

\author{
$(1952-2015)^{1}$
}

\author{
Glória Estevinho
}

- Enviado em 16/04/2016

- Aprovado em 20/05/2016

\section{RESUMO}

O que se propõe para este artigo é a análise de quem foram os Diretores do BNDES (Banco Nacional do Desenvolvimento Econômico e Social), uma instituição criada em 1952 e voltada para financiar, a longo prazo, a realização de investimento em todos os segmentos da economia de âmbito social, regional e ambiental, até os dias de hoje. Pretendemos verificar se estes indivíduos formam, em seu conjunto, uma elite política e administrativa nesta instituição e quais foram as formas de acesso a esse cargo: por meio de mérito/carreira tecnocrata ou por vias de parentesco/nepotismo, ou ambos. O método de análise utilizado para se compreender os diretores do BNDES será o prosopográfico. A partir da prosopografia busca-se entender o perfil geral destes diretores e de que maneira isto influenciaria nas diretrizes adotadas por esse banco. Portanto, o problema que se coloca é identificar esta "elite política/administrativa”, fundada sobre pesquisas empíricas. Esse estudo se faz necessário e se justifica, pois pouco ou nada se sabe sobre quem foram e qual o perfil destes diretores do BNDES. Esta análise específica a que se propõe este trabalho pode contribuir para a discussão mais ampla sobre o que é o Brasil e sua formação e mesmo o processo de formação dessa elite promovido no século XX pelo governo Vargas.

Palavras-chave: BNDES. Prosopografia. Tecnocracia. Parentesco

\section{INTRODUÇÃO}

O presente projeto é uma tentativa de transformar um acontecimento histórico e social, como a criação de uma instituição de fomento ao desenvolvimento econômico e social o Banco Nacional de Desenvolvimento Econômico - BNDE, em um estudo sociológico. O BNDE - nasce em 20 de junho

\footnotetext{
${ }^{1}$ Uma versão preliminar desse trabalho foi apresentada no GT1: INSTITUIÇÕES E PODER: PARENTESCOS E GENEALOGIAS do VII Seminário Nacional de Sociologia e Política da UFPR realizado de 11 a 13 de maio de 2016 em Curitiba.
}

2 Graduada em Ciências Sociais pela Universidade Federal do Paraná. Especialista em Sociologia Política pela UFPR. Endereço eletrônico: estevinho_gomes@ hotmail.com 
de 1952, através da Lei $\mathrm{n}^{\circ}$ 1628. A aprovação da Lei que o criou culmina com um processo de modernidade cuja, conjuntura busca adequação a um padrão mundial. Esse padrão mundial é o estabelecido pela industrialização sendo que para o Brasil vale a corrida pela adequação ao mercado internacional. Em termos de administração pública viveu-se o Estado Novo, que foi a porta de entrada para o desenvolvimentismo, como tentativa de adequar o país a tais padrões. As características econômicas mantiveram-se com base agrícola, o que torna impraticável sua manutenção, em função de um processo de industrialização crescente a nível mundial, o modo de vida rural torna-se obsoleto face as novas demandas. Diante desse impasse os hábitos bucólicos - ou o modo de vida no campo - de outrora cedem espaço ao frenesi do capitalismo e é, nesse cenário de transição, que a aprovação, da citada lei, tem, por origem política, o desenvolvimento econômico. Sua trajetória de formação, acontece num momento em que a economia caminha para promover transformações na infraestrutura e em toda a conjuntura social, sua proposta de criação é auxiliar no investimento e desenvolvimento econômico do país.

A década de 1950 é marcada por mudanças comportamentais, tecnológica, culturais e econômicas. As características de uma economia de base agrícola gradativamente são substituídas. O contexto vivido, é o da valorização do esporte e a conquista de títulos, especialmente no futebol ${ }^{3}$ - o que se efetiva em 1958 na Suécia. No aspecto cultural destaca se a I Bienal Internacional do Museu de Arte Moderna de São Paulo, tornando conhecidas obras de vários países. No cinema, os filmes de baixo custo garantiam o debate a temas focados a realidade do país. Na música, ao final da década, surge a Bossa Nova. Assim, nesse cenário, as discussões político-econômicas tentam definir os rumos do país tendo como eixo temático, principal, o monopólio do petróleo.

A política nacional vive o segundo mandato da Era Vargas cujas características são as do nacionalismo e do populismo. Getúlio Vargas foi presidente do Brasil por 15 anos e autor de muitas transformações em termos de legislação e investimentos no Estado. Sua primeira fase vai de 1930 a 1945 e é marcada pela criação de instituições que regulamentam o trabalho, bem como leis que conferem garantias ao trabalhador. Em seu segundo mandato, acontece a criação da Petrobrás e do BNDES sendo, esse momento histórico de nosso interesse investigar. É, portanto, nesse segundo mandato, que ocorre a criação do nosso objeto de estudo. No campo político, Getúlio Vargas retorna ao poder pelo voto popular. Candidatou-se pelo PTB e recebeu apoio do Partido Social Progressista (PSP), vencendo o pleito de 1950 com 48,7\% dos votos. Esta nova fase foi marcada por importantes iniciativas nas áreas social e econômica. Porém, as pressões de grupos

\footnotetext{
${ }^{3}$ No Brasil em 1950 acontece a copa do mundo. O Maracanã é construído no Rio de Janeiro para sediar o evento.
} 
oposicionistas civis e militares desencadearam uma aguda crise política que levou Vargas a interromper seu mandato com um ato que atentou contra sua própria vida: o suicídio.

Nosso foco centra-se nos preparativos para a modernização do país e em alguns acordos que dão subsídio para a criação do BNDE com o propósito de financiar o desenvolvimento nacional através do reaparelhamento econômico. Estes acordos, originam-se no final da primeira fase do governo Getúlio Vargas e os rumos seguidos a sua sucessão. O ano era o de 1945, que historicamente marca o fim da II Guerra Mundial e dá margem a Guerra Fria, o partido dominante no Brasil ainda é o PSD (Partido Social Democrático), ao qual Eurico Gaspar Dutra se vincula e, mesmo a UDN (União Democrática Nacional) tendo lançado o brigadeiro Eduardo Gomes na disputa, o apoio de Getúlio Vargas não deixou espaço para dúvidas. As urnas respondem com 51\% de preferência. Desse modo, entre outras decisões tomadas, o plano SALTE ${ }^{4}$ é criado e torna-se o precursor do desenvolvimento econômico, na tentativa do reaparelhamento do Estado.

Assim, nessa segunda fase de seu governo, é montada uma Comissão Mista entre o Brasil e os Estados Unidos, como resultado de negociações conduzidas durante o governo Dutra, com o propósito de realizar estudos macroeconômicos e, tendo como objetivo, o estudo dos chamados pontos de estrangulamento da economia brasileira. Essa comissão teve duração de dois anos e meio e permitiu, num primeiro diagnóstico, estabelecer a infra-estrutura necessária para a industrialização. Essa produção é feita por nomes como o de: Eugênio Gudim, Otávio Gouveia de Bulhões e Valter Lima Sarmanho ${ }^{5}$, e gerou uma perspectiva setorial que foi publicada em 17 volumes, contendo 41 macroprojetos considerados prioritários para o desenvolvimento econômico brasileiro.

Concluída a gestão, eis que nasce o BNDE em 1952, sob a égide de formular e executar a política nacional de desenvolvimento econômico, porém, ao longo de sua existência, interesses distintos avançam e povoam o cenário nacional, conforme demonstra a linha do tempo a seguir:

\footnotetext{
${ }^{4}$ Suas iniciais fazem alusão as intenções do governo no atendimento a população e como projeto desenvolvimentista. Saúde, Alimentação, Transporte e Educação - SALTE.

${ }^{5}$ Nome que compõe o quadro dos presidentes do BNDE ainda na administração de Vargas e tem afinidade parental com o presidente. Esses nomes dão indícios da formação da tecnocracia brasileira, cujas origens datam desta época.
} 
INTERESSES QUE POVOAM O CENÁRIO NACIONAL A PARTIR DA DÉCADA DE 1950

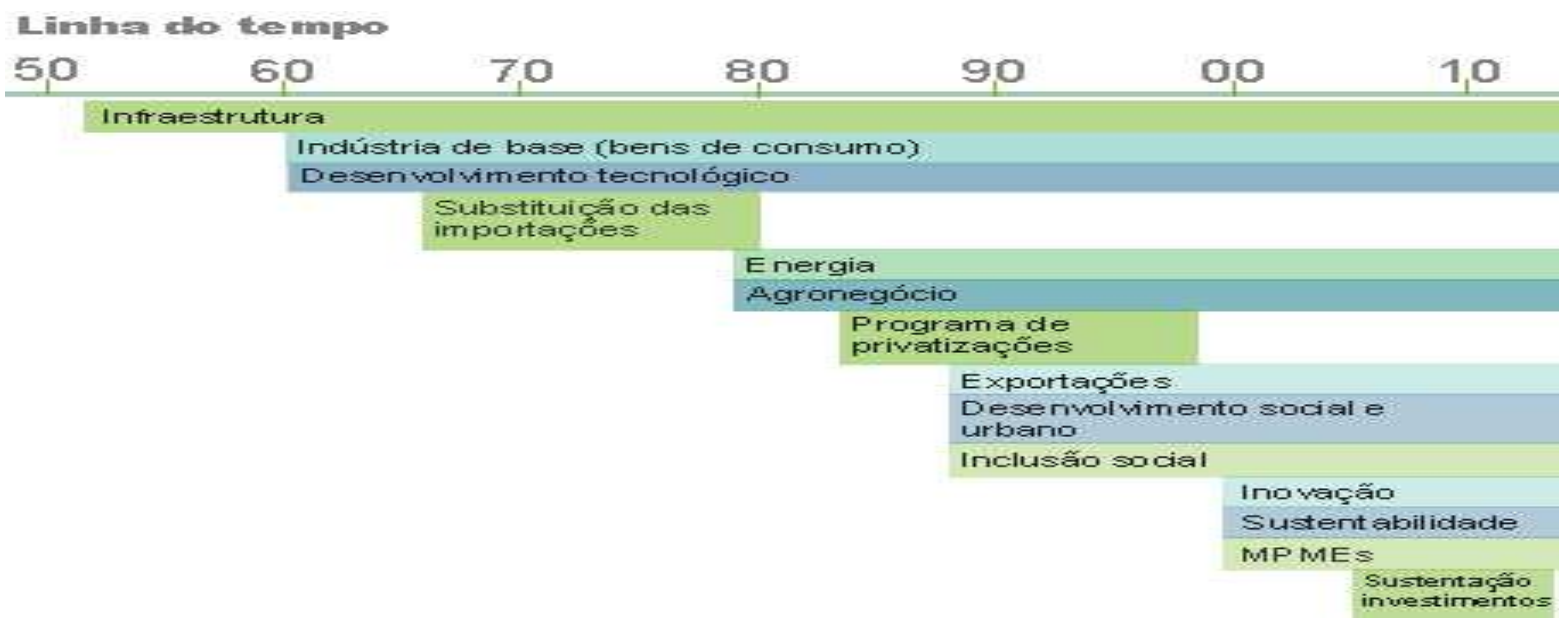

FONTE: http://www.ipea.gov.br/. Acesso 29.fev.2016

Nas décadas de 1950 e 1960 predomina no Brasil a política desenvolvimentista incentivada pelo então presidente do Brasil Getúlio Vargas (1951-1954), onde o fundamental era a implementação da indústria. Sendo que os primeiros investimentos centram-se no reaparelhamento dos portos e ferrovias bem como na ampliação do potencial elétrico e a associação com os institutos de pesquisa, tais como a CEPAL e a FGV, que se encarregavam de fornecer análise de dados macroeconômicos e dados sobre a evolução da renda nacional, respectivamente. Já nas décadas de 1960 e 1970 começam a ganhar corpo a indústria de base - a produção de bens e consumo - e o desenvolvimento tecnológico, é um período de crescimento econômico denotado pelo aumento das cidades, coordenados pelos programas do sistema nacional de habitação $\mathrm{BNH}$, que cuidavam tanto do desenvolvimento das cidades financiando residências tanto quanto o estatal em grandes obras que davam continuidade em setores básicos como energia e transportes. Fica estabelecido, neste período histórico,o tripé de sustentação da economia para as décadas seguintes : o Estado - com o estímulo aos empresários via recursos do $\mathrm{BNDES}^{6}$ para expansão dos negócios, as multinacionais especialmente as montadoras e o grande capital nacional. Os investimentos em conjunto

${ }^{6}$ O I Plano Nacional de Desenvolvimento (PND), sob a responsabilidade do ministro do Planejamento, João Paulo dos Reis Velloso, estabeleceu as diretrizes para o período 1972-4, prevendo um crescimento do PIB em torno de $8 \%$ a $9 \%$ ao ano, uma inflação anual abaixo dos $20 \%$ e um aumento das reservas cambiais em pelo menos US\$ 100 milhões. O BNDE era presidido por Marcos Pereira Vianna de 1969 a 1979. 
mantinham a ideia em voga de executar, em todos os setores básicos da economia, um forte programa de substituição de importações, contando com a experiência de 20 anos em análise de viabilidade de projetos e no gerenciamento de créditos e, sendo esta peça, a chave de indução ao desenvolvimento.

A manutenção desse tripé implicou no aparecimento de estatais ${ }^{7}$ que assegurassem os insumos ao setor automobilístico. Muitos foram os investimentos com o objetivo de consolidar a indústria no país, desse modo, o governo se empenhava em substituir importações, seu agente financiador, participou ativamente desse processo, sobretudo no apoio à empresa privada nacional, considerada o elo mais vulnerável no tripé econômico. Para tanto, precisou adequar-se à mudança, então em 1974, passa a gerenciar os recursos do Programa de Integração Social (PIS) e do Programa de Formação do Patrimônio do Servidor Público (Pasep), criados no início da década com uma parcela do lucro das empresas, formando um fundo de amparo aos trabalhadores (FAT). A maior parte desses recursos destinava-se a aplicações em novos investimentos, desde que estes não fossem estrangeiros, não proviessem de municipalidades e não servissem para compor capital de giro no comércio ou na prestação de serviços. O PIS-Pasep significou uma mudança profunda para o BNDES, com forte incremento da capacidade de apoio aos investimentos.

A história seguiu seu curso e o banco que angariou recursos da produção nacional e do trabalhador, mudou suas características em função de acordo com as políticas interessadas na continuidade ou não do programa nacional de desenvolvimento, ao qual o cargo ocupado na instituição, enquanto presidente, fazia se mister. Com essas iniciativas, o BNDES acompanhava o processo de transformação pelo qual vinha passando o mercado de crédito e de capitais desde a reforma que, na década de 60, modificara totalmente o Sistema Financeiro Nacional, passando pelo crédito imobiliário rural, os bancos para captação de depósitos à vista, os bancos de investimento, as financeiras e as Bolsas de Valores, com diversas formas de captação e aplicação. Contudo, não ocorrera o esperado aumento da oferta de financiamentos privados de longo prazo, e a principal razão disso era a escalada inflacionária. A nova estratégia do BNDES logo começou a dar resultados. O Banco detectava os setores que considerava importante desenvolver e buscava empresários que, mediante condições favoráveis, se dispusessem a ocupar esses nichos. Na época, a correção monetária dos débitos se limitava a 20\%. A política seguida pelo Banco correspondia

\footnotetext{
${ }^{7}$ Criou-se a Siderbrás uma combinação de particular (Villares, Barra Mansa e Riograndense) e as estatais (Vale do Rio Doce, CSN, Usiminas) e multinacionais (Kawasaki Steel e Nippon Steel) que dava suporte ao crescimento da indústria de bens duráveis, além das produtoras de matérias básicas do ramo petroquímico que alavancaram o projeto de crescimento econômico.
} 
assim à estabelecida pelo governo: fornecer juros subsidiados como forma de incentivar o desenvolvimento de setores econômicos que eram considerados estratégicos e não vinham sendo devidamente explorados. Foram os financiamentos do BNDES, que viabilizaram importantes projetos nos ramos do aço, do papel e celulose, da petroquímica, da soda cáustica e cloro, do estanho, zinco e alumínio, do cimento e dos fertilizantes. Desse modo é que empresas nacionais de papel e celulose, setor até então carente de financiamento, fizeram uso dos incentivos do BNDES para ampliar e modernizar suas fábricas, alcançando assim as metas de auto suficiência pretendidas pelo governo.

No setor de equipamentos básicos, o Banco não só concedia financiamentos a fabricantes, como também facilitava através da Finame o crédito para comercialização, adotando taxas de juro decrescentes na razão direta da nacionalização do equipamento, tendo como critérios o conteúdo tecnológico, o caráter pioneiro da fabricação e a participação da engenharia brasileira. Empresas como a Cofap, a Villares Equipamentos, a Máquinas Piratininga e a Bardella receberam forte apoio da Finame. Outra prova da visão modernizadora do Banco eram os investimentos numa área que, embora ainda nova e pouco conhecida, viria a revolucionar o mundo nos anos seguintes: a informática. Em meados da década de 70, o BNDES engajou-se no Projeto Cobra, destinado a desenvolver, fabricar e comercializar sistemas de eletrônica digital e associados. O Banco atuava mediante os financiamentos diretos e com participação na Empresa Digital Brasileira (Digibrás). Em 1975, o BNDES também realizou contratos no campo dos componentes eletrônicos. Um deles foi assinado com a Telebrás e o Laboratório de Microeletrônica da USP, visando a fabricar lâminas de cristal de três polegadas para circuitos integrados, até então importados. Na tecnologia de ponta, outro investimento importante se relacionava a um projeto anterior, o Centro Técnico Aeroespacial, em São José dos Campos. O BNDES passou a financiar as indústrias que utilizassem tecnologia desenvolvida pelo CTA para fabricar, em série, equipamento aeronáutico e aeroespacial ainda não produzido no país. Em 1977, instituiu-se o Prêmio BNDES de Economia, com o objetivo de estimular a pesquisa no campo da ciência econômica pura ou aplicada, segundo a perspectiva nacional, regional ou setorial. Com essas iniciativas obteve a projeção do banco na política nacional e internacional com o concomitante crescimento econômico e a formação de uma tecnocracia capaz de dar suporte a essas alçadas investidoras do projeto nacional, proposto pelo governo.

A troca de governo, ao longo da atuação do banco lhe confere significativas mudanças nacional, seguindo prerrogativas imposta, de um lado pelo governo e, de outro, pelo mercado internacional, conforme orientações dos especialistas empenhados em elevar a economia brasileira. 
Nesse contexto, já podemos citar uma dependência ao Fundo Monetário Internacional (FMI) criado no pós-guerra e com o objetivo de alavancar as nações para a reconstrução econômica dentro do sistema capitalista, e que abrigava todas as nações que dele quisessem participar. Esse novo ordenamento do mundo, seria caracterizado pelo fortalecimento do capitalismo e pela obediência a instituições internacionais regidas pelo principio democrático no qual todos se fariam representar igualmente. Esses princípios, no decorrer da dependência, acabam interferindo na política econômica dos países devedores de forma extremamente autoritária. A dependência ganha o discurso político e pulveriza um programa de desestatização que acontece na década de 1995 a 2003, com o governo Fernando Henrique Cardoso.

O ano de 2009 abre um processo de investigação de crimes de lavagem de recurso relacionados ao ex deputado federal José Janene, em Londrina, no Paraná, Além do ex-deputado, estavam envolvidos nos crimes os doleiros Alberto Youssef e Carlos Habib Chater. Sendo que Alberto Youssef, já havia sido investigado e processado por crimes contra o sistema financeiro nacional e de lavagem de dinheiro no caso Banestado. Assim, em março de 2014, tem início a primeira fase ostensiva da operação e através do monitoramento das comunicações dos doleiros revela que Alberto Youssef, mediante pagamentos feitos por terceiros, fez doações ao ex-diretor de Abastecimento da Petrobras Paulo Roberto Costa. Em 2014, numa a segunda fase, chamada, ostensiva da operação Paulo Roberto Costa é preso acusado, junto com seus familiares, pelo crime de obstrução à investigação e de organização criminosa. $\mathrm{O}$ avanço das investigações apontam para a existência de um grande esquema de corrupção e lavagem de dinheiro na Petrobras. Assim é que, quatro pessoas, são citadas, incluindo o ex-diretor da área Internacional da Petrobras Nestor Cerveró, que é surpreendido e preso em janeiro de 2015, ao voltar de Londres ${ }^{8}$. Junto a grampos telefônicos, programa de deleção premiada as investigações avançam, estampam as capas de revistas e jornais e são matéria de interesse público e internacional até recaírem na CPI do BNDES, solicitada pelo Deputado Federal Rubens Bueno ( PPS/PR), pede investigações sobre supostas irregularidades ocorridas entre os anos de 2003 e 2015, relacionadas a concessão de empréstimos concedidos a países como Angola e Cuba. ${ }^{9}$ Porém, em 2016, quando da conclusão do relatório José

\footnotetext{
8 Disponível em http://lavajato.mpf.mp.br/atuacao-na-1a-instancia/investigacao/historico/por-onde-comecou. Acesso em 16.abril.2016
} 9 Disponível em http://g1.globo.com/politica/noticia/2015/08/cpi-do-bndes-e-instalada-na-camara-dos-deputados.html.
Acesso em 16.abril.2016 
Rocha (PR/PA), contrariando a oposição não pede indiciamento do banco e sugere uma série de alterações na forma de governança e nas práticas institucionais do BNDES. ${ }^{10}$

Desse modo, a história da criação do BNDES se mistura a história do Brasil. A investigação proposta da trajetória do banco vai permitir uma leitura sociológica dos fatos devendo interessas aos mais variados campos do saber científico.

\section{ESTUDO PROSOPOGRÁFICO}

A análise sociológica pode se valer de uma técnica, pouco utilizada entre os estudiosos e pesquisadores da área de humanas, segundo Heinz, que é o da biografia coletiva - a prosopografia. Flávio Heinz é o organizador do livro: História social das elites e , no qual, assina um capítulo para contar como essa técnica pode ajudar os estudos sociológicos, bem como acrescentar dados significativos a construção de um determinado período histórico, onde grandes mudanças são observadas no conjunto da sociedade a partir da sistematização das biografias. Tomando, por base, essa observação, considero pertinente o uso desta metodologia para o estudo dos diretores do BNDES cujas biografias permite visualizar a instituição familiar (esta diretamente ligada as análises do parentesco, quer seja por nascimento, quer seja pelo casamento), a instituição escolar (que pode auxiliar nas interpretações sobre aspectos da formação e, ao grau de representação social que possui, sendo significativo o campus, no sentido empregado por Bourdieu ) e, ainda aspectos ligados a carreira e todo um sistema de relações pessoais estabelecidos por conta do pertencimento a uma elite no poder.

O método da prosopografia é, conforme citado pelo autor, como uma alternativa de análise nas pesquisas desenvolvidas por historiadores e Cientistas Sociais, em franco crescimento entre os pesquisadores. Esse tipo de metodologia atende a alguns requisitos de pesquisa e favorecem o quantitativo pesquisado. Essa é uma possibilidade dentro do estudo das elites porque permite uma espécie de mapa de trajetória coletiva. Essa proposta, faz menção as vantagens teóricometodológica e historiográfica, das micros histórias social das elites, por permitir um diagnóstico

\footnotetext{
${ }^{10}$ Disponível em http://g1.globo.com/politica/noticia/2016/02/relator-contraria-oposicao-e-nao-pede-indiciamentos-nacpi-do-bndes.html. Acesso em 16.abril.2016
} 
detalhado das personalidades que, em um dado período tomaram a frente no processo decisório nacional ocupando cargos dentro de uma estatal criada com o intuito de promover o desenvolvimento econômico e social do país. Por esse intermédio a pesquisa enriquece os conteúdos sociais que englobam as elites e a formação de um poder manifesto em forma de cargo específico e que permite galgar outras instâncias de poder. Esse tipo de estudo é importante porque sugere visualizar as possíveis conversões e reconversões que o poder assume. Outra vantagem, neste método investigativo, é o da produção de uma lista biográfica de cada ator social com dados sobre os seus acúmulos de capitais sociais.

A valorização dos capitais adquiridos passa, dentro dessa técnica, pela superação do individuo e trata dos aspectos coletivos da vida social. No estudo biográfico, as informações se situam no plano individual e levam em conta as conquistas pessoais, o capital econômico denotando as aquisições pessoais e familiares que sugerem as fortunas pessoais e privilégios do pesquisado. Entendendo que esse tipo de estudo seja importante e que apresenta de maneira breve e eficaz o prestígio dos personagens escolhido é que, o autor, vai sugerir a formulação do dicionário histórico biográfico. Assim, tomando por referência esse tipo de estudo, considero necessária essa averiguação no âmbito deste estudo, pois vai procurar a leitura social dos conhecimentos adquiridos em um período da história na qual transformações significativas indicam dependência do capital estrangeiro, desenvolvimento estrutural e econômico interno, troca de governo e seus reflexos sociais, emergência de grupos específicos e a formação da tecnocracia, habilitada por um campo comum, além da possível relação de parentesco, como alavanca ou não, a cargos estratégicos dentro da política nacional.

Os diretores do BNDES são os representantes de uma elite intelectual e social, cujo domínio num período da história do Brasil, promoveram transformações, associados aos interesses das sucessões presidenciais, em toda a estrutura e organização. Essas transformações cabiam a profissionais oriundos de determinados campus, específicos ao atendimento de demandas históricas. Assim é que engenheiros são contratados e impulsionam aberturas de materiais de metal pesado, criando a infraestrutura necessária a esse fomento. Outra etapa do desenvolvimento, substitui os engenheiros por militares e, depois, economistas, compondo o cenário nacional com a figura dos tecnocratas e redirecionando o discurso desenvolvimentista a uma lógica capitalista, numa relação de dependência constante ao capital internacional vinculando seus feitos a uma política 
inflacionária. Eclodem os economistas ligados do núcleo cepalino ${ }^{11}$ como estudiosos da economia na tentativa do restabelecimento econômico. É, nesse aspecto, que a prosopografia se constitui numa fonte útil de valorização de uma identidade profissional. Esses atores sociais e políticos contribuem com a formação de uma elite pensante e permite, pela técnica de pesquisa, sistematizar suas histórias pessoais e comparar com as de outros atores traçando uma espécie de trajetória do desenvolvimento pessoal que de certo modo indica o curso da história, como no caso do BNDES. Outro aspecto a ser considerado nessa trajetória são os parentescos cruzados que podem render muitas coincidências indicando o "peso" do indivíduo nas estratégias de acesso as instituições. Abaixo relação dos presidentes do BNDES que farão parte desse estudo prosopográfico ${ }^{12}$.

\section{LISTA DE PRESIDENTES DO BNDES}

\begin{tabular}{|c|c|c|c|c|}
\hline № & Nome & Início & Fim & Presidente \\
\hline 1 & Ari Frederico Torres & julho de 1952 & junho de 1953 & \multirow{2}{*}{ Getúlio Vargas } \\
\hline \multirow{2}{*}{2} & \multirow{2}{*}{ Válder Lima Sarmanho } & junho de 1953 & agosto de 1954 & \\
\hline & & agosto de 1954 & fevereiro de 1955 & \multirow{2}{*}{ Café Filho } \\
\hline \multirow{2}{*}{3} & \multirow{2}{*}{ Glycon de Paiva Teixeira } & março de 1955 & novembro de 1955 & \\
\hline & & novembro de 1955 & fevereiro de 1956 & Nereu Ramos \\
\hline 4 & Lucas Lopes & fevereiro de 1956 & junho de 1958 & \multirow{3}{*}{ Juscelino Kubitschek } \\
\hline 5 & Roberto Campos & agosto de 1958 & julho de 1959 & \\
\hline 6 & Lúcio Martins Meira & julho de 1959 & fevereiro de 1961 & \\
\hline 7 & José Vicente Faria Lima & fevereiro de 1961 & setembro de 1961 & Jânio Quadros \\
\hline 8 & Leocádio de Almeida Antunes & setembro de 1961 & junho de 1963 & João Goulart \\
\hline 9 & José Garrido Torres & julho de 1964 & março de 1967 & Castelo Branco \\
\hline 10 & Jayme Magrassi Sá & março de 1967 & outubro de 1970 & Costa e Silva \\
\hline \multirow{2}{*}{11} & \multirow{2}{*}{ Marcos Pereira Vianna } & outubro de 1970 & março de 1974 & Emílio Garrastazu Médici \\
\hline & & março de 1974 & março de 1979 & Ernesto Geisel \\
\hline 12 & Luiz Antônio Sande de Oliveira & março de 1979 & setembro de 1983 & \multirow{3}{*}{ João Figueiredo } \\
\hline 13 & Jorge Lins Freire & setembro de 1983 & outubro de 1984 & \\
\hline 14 & $\begin{array}{l}\text { José Carlos Perdigão } \\
\text { Medeiros da Fonseca }\end{array}$ & outubro de 1984 & março de 1985 & \\
\hline 15 & Dilson Funaro & março de 1985 & agosto de 1985 & José Sarney \\
\hline
\end{tabular}

11 Comissão de Econômica para América Latina (CEPAL) foi estabelecida pela resolução 106 (VI) do Conselho Econômico e Social, de 25 de fevereiro de 1948, e começou a funcionar nesse mesmo ano. fundada para contribuir ao desenvolvimento econômico da América Latina, coordenar as ações encaminhadas à sua promoção e reforçar as relações econômicas dos países entre si e com as outras nações do mundo. Posteriormente, seu trabalho foi ampliado aos países do Caribe e se incorporou o objetivo de promover o desenvolvimento social.

${ }^{12}$ Consultar no ANEXO ao final do artigo a ficha biográfica de cada um dos 33 diretores elaborada pela autora. 


\begin{tabular}{|c|c|c|c|c|}
\hline 16 & André Franco Montoro Filho & agosto de 1985 & janeiro de 1987 & \\
\hline 17 & Márcio Fortes & janeiro de 1987 & setembro de 1989 & \\
\hline 18 & Ney Fontes de Melo Távora & outubro de 1989 & março de 1990 & \\
\hline 19 & Eduardo Modiano & março de 1990 & outubro de 1992 & Fernando Collor de Mello \\
\hline 20 & Antônio Barros de Castro & outubro de 1992 & março de 1993 & \multirow{3}{*}{ Itamar Franco } \\
\hline 21 & Luiz Carlos Delben Leite & março de 1993 & agosto de 1993 & \\
\hline 22 & Pérsio Arida & setembro de 1993 & janeiro de 1995 & \\
\hline 23 & Edmar Bacha & janeiro de 1995 & novembro de 1995 & \multirow{7}{*}{$\begin{array}{l}\text { Fernando Henrique } \\
\text { Cardoso }\end{array}$} \\
\hline 24 & $\begin{array}{l}\text { Luiz Carlos Mendonça de } \\
\text { Barros }\end{array}$ & novembro de 1995 & abril de 1998 & \\
\hline 25 & André Lara Resende & abril de 1998 & novembro de 1998 & \\
\hline 26 & $\begin{array}{l}\text { José Pio Borges de Castro } \\
\text { Filho }\end{array}$ & novembro de 1998 & julho de 1999 & \\
\hline 27 & Andrea Sandro Calabi & julho de 1999 & fevereiro de 2000 & \\
\hline 28 & Francisco Gros & fevereiro de 2000 & janeiro de 2002 & \\
\hline 29 & Eleazar de Carvalho Filho & janeiro de 2002 & janeiro de 2003 & \\
\hline 30 & Carlos Lessa & janeiro de 2003 & novembro de 2004 & \multirow{4}{*}{ Luiz Inácio Lula da Silva } \\
\hline 31 & Guido Mantega & novembro de 2004 & março de 2006 & \\
\hline 32 & Demian Fiocca & março de 2006 & maio de 2007 & \\
\hline \multirow{2}{*}{33} & \multirow{2}{*}{ Luciano Coutinho } & maio de 2007 & janeiro de 2010 & \\
\hline & & janeiro de 2010 & maio de 2016 & Dilma Rousseff \\
\hline 34 & Maria Silvia Bastos Marques & Maio de 2016 & & Michel Temer \\
\hline
\end{tabular}

Fonte: "Galeria dos presidentes". Banco Nacional de Desenvolvimento Econômico e Social (BNDES). Acesso em 27.maio. 2016

\section{ESTUDOS DE TECNOCRACIA}

A base do pensamento tecnocrático é a ciência, desse modo, essa foi a prática adotada pelo governo brasileiro quando seu projeto era o desenvolvimentismo, após criação BNDES, a ideia é a do uso de métodos científicos para diretrizes governamentais. Assim o quadro de presidentes que compõe a instituição são de profissionais que denotam o pertencimento a um campus específico de formação somado ao acumulo de titulação, inclusive no exterior com especializações inclusive em academias internacionais que configuram a habilidade necessária ao referido cargo. Ser tecnocrata é, por definição, aquisição de sólidos conhecimentos bem como habilidades conquistadas na prática de sua área de atuação, ou seja, o tecnocrata era detentor de uma versão profissional, dotado de conhecimentos específicos que superavam a cultura geral empregada com base em preceitos políticos, econômicos filosóficos dos homens do governo. Assumir tal cargo só era possível a 
convite do Presidente da República, normalmente. Por vezes, participar de um campus e construir um sistema de relações pessoais era o caminho a trilhar para chegar à Presidência do banco. Uma vez ocupando o cargo, várias outras empresas bancos ou cargos políticos lhes eram associadas. Essa associação garantia a aprovação dos projetos a serem consolidados no país, assim como na década em que o banco tem que responder ao projeto político de industrialização que abarca as décadas de 1970 a 1980, por exemplo.

Maria de Lourdes M. Covre relata em seu livro : A fala dos homens, onde procura construir mosaicos de figuras indicativas da concepção do mundo do bloco ideológico, verificando qual tipo de racionalidade explica a persistência do chamado Estado autoritário pós 1964. Segundo a autora, esses tecnocratas servem aos interesses do capital monopolista no Brasil e cumprem a três funções primordiais: assegurar a realização do pacto da interdependência; manter a coesão entre frações do capital e compor uma "mediação" entre dominantes e dominados. Os intelectuais que compõem o quadro da presidência do BNDES são profissionais que atendem a essas características. A apresentação do Estado nesse momento é o uso de todo um aparato técnico que sustenta a burocracia

\section{ESTUDOS DE PARENTECO}

A proposta de levantar a biografia coletiva dos diretores do BNDES pretende identificar entre os Presidentes da instituição as possibilidades, ou não de um quadro de nepotismo, onde os favorecimentos por parentesco ou consanguinidade sejam a condição de adesão ao cargo. Tratar aspectos desta instituição é referir-se a construção do país além de sua dinâmica de funcionamento onde determinados pertencimentos campus hábitos se fazem presente e

Foi Oliveira (2001) que chamou a atenção pra essa relação de parentesco, identificada como nepotismo , em sua publicação sobre o Paraná, mostrando o quanto a política está viciada nesta pratica da perpetuação de famílias no poder . O nepotismo é uma prática que sobrevive pela conivência de outros poderes, mas principalmente porque, de modo geral temos a atitude, como a denunciada por Bertold Brecht, de um analfabeto político que não se interessa por política e estufa o peito ao afirmar isso ausentando-se do exercício de cidadania ou vendendo seu voto por ignorar o financiamento das mazelas sociais promovidas por esse analfabetismo. Tais práticas demonstra a fragilidade das instituições políticas e estão associadas as questões próprias das desigualdades 
sociais, da patronagem e ao clientelismo. Desse modo, o Estado perde suas características de público e transforma-se numa agência de favores e de parentesco, partidos políticos também perdem suas características, dentro do sistema democrático, por manter uma relação de dependência às famílias, as únicas beneficiadas por esse modelo. Tradicionalmente essa prática é característica do setor público, ${ }^{13}$ porém não está descartada como prática de vários outros segmentos da vida social e, desse modo, considero ser possível pela via da construção das biografias coletiva designar esse olhar a composição dos Presidentes do BNDES quando assumem o cargo se estão comprometidos anteriormente com cargos políticos ou ele surge por consequência da posse, ou seja, o grau de representatividade social que o cargo confere pode ser estendido a vida pública?

\section{CONSIDERAÇÕES FINAIS}

A partir da prosopografia busca-se entender o perfil geral destes diretores e de que maneira isto influenciaria nas diretrizes adotadas por esse banco. Portanto, o problema que se coloca é identificar esta "elite política/administrativa", fundada sobre pesquisas empíricas. Esse estudo se faz necessário e se justifica, pois pouco ou nada se sabe sobre quem foram e qual o perfil destes diretores do BNDES. Esta análise específica a que se propõe este trabalho pode contribuir para a discussão mais ampla sobre o que é o Brasil e sua formação e mesmo o processo de formação dessa elite promovido no século XX pelo governo Vargas.

Esse estudo terá por método a prosopografia, ao levantar a biografia individual dos diretores do BNDES desde a criação do banco até as manchetes que citam o banco na comissão parlamentar de inquérito CPI serviu para delinear o perfil de seus diretores em diferentes governos e com diferentes projetos políticos.

\section{REFERÊNCIAS}

BNDES Um banco de história e de e de futuro disponível em:https://www.google.com.br/?gws_rd=ssl\#q=historia+bndes+pdf

COVRE, Maria de Lourdes Manzini. A fala dos homens: análise do pensamento tecnocrático 1964198, Ed. Brasiliense, 1983, 327p.

\footnotetext{
13 Entrevista concedida por Ricardo Costa Oliveira disponível em: http://www.gazetadopovo.com.br/vida-publica/apolitica-vem-se-tornando-negocio-de-familia-no-parana-daedg5khe2xep7latvv9o0kem pesquisa feita em 16/03/2016
} 
HEINZ, Flávio. História social das elites, disponível em:http://observatory-elites.org/wpcontent/uploads/2011/11/Historia-social-de-elites-FLAVIO-HEINZ.pdf

A Instituição Conselho e a Democracia: na história do Brasil e no conselho nacional de política cultural, Centro de Convenções Ulysses Guimarães Brasília/DF - 16, 17 e 18 de abril de 2013. VI Congresso Consad - Gestão Pública disponível em:http://consadnacional.org.br/wpcontent/uploads/2013/05/068-A-INSTITUI\%C3\%87\%C3\%83O-CONSELHO-E-ADEMOCRACIA-NA-HIST\%C3\%93RIA-DO-BRASIL.pdf

Perfil dos diretores do Banco Central do Brasil nos governos Cardoso, Lula e Dilma; Eric Gil Dantas (ufpr; nusp); Adriano Codato (ufpr; nusp) ; Renato Perissinotto (ufpr; nusp), disponível em: http://observatory-elites.org/wp-content/uploads/2012/06/wp-observatory-n.10-2014.pdf

OLIVEIRA, Ricardo Costa de (2001).

Curitiba: Editora Moinho do Verbo.

Sites consultados

http://cpdoc.fgv.br/producao/dossies/AEraVargas2/artigos/EleVoltou/BNDE

http://brasilescola.uol.com.br/sociologia/transformacoes-socioeconomicas-no-brasil-decada-50.htm http://www.bndes.gov.br/SiteBNDES/export/sites/default/bndes_pt/Galerias/Arquivos/conheciment o/livro50anos/Livro_Anos 70.PDF

http://fatoonline.com.br/conteudo/6984/nasce-a-cpi-do-bndes-gerada-por-cunha-e-oposicao-paradesgastar-governo?or $=$ busca $\& \mathrm{p}=\mathrm{b} \& \mathrm{i}=12 \& \mathrm{v}=0 \& \mathrm{q}=\mathrm{cpi}+\mathrm{bndes}$ 


\title{
ANALYSIS OF PROSOPOGRAPHIC BNDES' DIRECTORS (1952-
}

\section{5)}

\begin{abstract}
What is proposed for this article is the analysis of who were the directors of the BNDES (National Bank for Economic and Social Development), an institution created in 1952 and dedicated to finance, long-term, the realization of investment in all segments of economy of social, regional and environmental context, to the present day. We intend to verify that these individuals form, as a whole, a political and administrative elite in this institution and what were the forms of access to this position: through merit / technocratic career or relationship pathways / nepotism, or both. The analysis method used to understand the directors of the BNDES will be prosopographical. From prosopography seeks to understand the general profile of these directors and how this would influence the guidelines adopted by that bank. Therefore, the problem that arises is to identify this "political elite / administrative", based on empirical research. This study is necessary and justified because little or nothing is known about who they were and what their profile directors of the BNDES. This particular analysis suggests that this work can contribute to the broader discussion of what is Brazil and its formation and even the process of formation of this elite promoted in the twentieth century by the Vargas government.
\end{abstract}

Key-words: BNDES. Prosopography. Technocracy. Kinship 


\section{ANEXO - FICHAS BIOGRÁFICAS DO DIRETORES DO BNDES}

\begin{tabular}{|c|c|}
\hline & 1 - DIRETOR: ARI FREDERICO TORRES \\
\hline & PRESIDENTE: GETÚLIO VARGAS \\
\hline & PERÍODO DA HISTÓRIA: REGIME DEMOCRÁTICO \\
\hline & GESTÃO: JULHO 1952/JULHO1953 \\
\hline & LOCAL E DATA DE NASCIMENTO: O1/10/1900 - PORTO ALEGRE \\
\hline & LOCAL E DATA DE MORTE: 09/02/1973 - SÃO PAULO \\
\hline & FORMAÇÃO/PROFISSÃO: ENGENHEIRO CIVIL \\
\hline & $\begin{array}{l}\text { CARREIRA: PRESIDENTE E FUNDADOR DO IPT - INSTITUTO DE PESQUISAS TECNOLÓGICAS. ABNT - } \\
\text { ASSOCIAÇÃO BRASILEIRA DE NORMAS TÉCNICAS. ABCP - ASSOCIAÇÃO BRASILEIRA DE NORMAS } \\
\text { TÉCNICAS. ABM - ASSOCIAÇÃO BRASILEIRA DE METAIS. CSN - CIA. SIDERÚRGICA NACIONAL. BNDE - } \\
\text { BANCO NACIONAL DE DESENVOLVIMENTO ECONÔMICO. BRASSINTER S.A. INDÚSTRIA E COMÉRCIO E A } \\
\text { COMPANHIA BRASILEIRA DE MATERIAL ELÉTRICO - COBREL. SECRETÁRIO DE VIAÇÃO E OBRAS PÚBLICAS } \\
\text { DE SÃO PAULO }\end{array}$ \\
\hline & FILIAÇÃO PARTIDÁRIA: \\
\hline & $\begin{array}{l}\text { PARENTESCO: FILHO DE CRISTIANO TORRES E DE ISABEL MAGALHÃES TORRES. ERA CASADO COM } \\
\text { MARIA APARECIDA BITTENCOURT TORRES, COM OUEM TEVE TRÊS FILHOS. }\end{array}$ \\
\hline
\end{tabular}




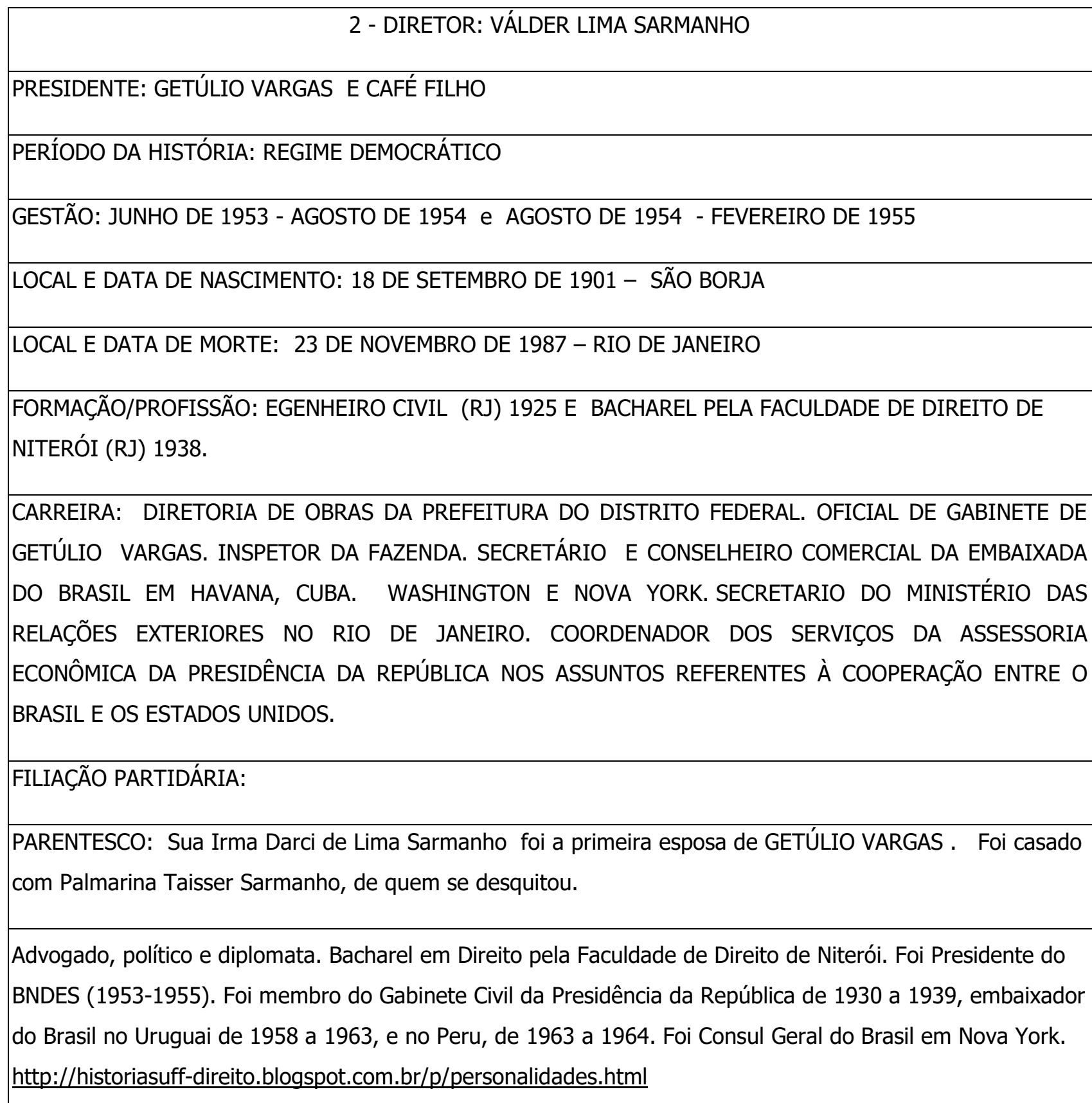




\begin{tabular}{|c|}
\hline 3 - DIRETOR: GLYCON DE PAIVA TEIXEIRA \\
\hline PRESIDENTE: CAFÉ FILHO E NEREU RAMOS \\
\hline PERÍODO DA HISTÓRIA: \\
\hline GESTÃO: MARÇO DE 1955 A NOVEMBRO DE 1955 - NOVEMBRO DE 1955 A FEVEREIRO DE 1956 \\
\hline LOCAL E DATA DE NASCIMENTO: 19/09/1902 - MINAS GERAIS \\
\hline LOCAL E DATA DE MORTE:16/07/1993 - RIO DE JANEIRO \\
\hline FORMAÇÃO/PROFISSÃO:ENGENHEIRO CIVIL \\
\hline $\begin{array}{l}\text { CARREIRA: CHEFE DO DEPARTAMENTO NACIONAL DA PRODUÇÃO MINERAL DO MINSTÉRIO DA } \\
\text { AGRICULTURA. DIRETOR DA DIVISÃO DE GEOLOGIA E MINERALOGIA. DIRETOR DA DIVISÃO DE } \\
\text { FOMENTO SERVIÇO E PRODUÇÃO. CHEFE DA PRODUÇÃO MINERAL E COORDENAÇÃO DA MOBILIZAÇÃO } \\
\text { ECONÔMICA. CONFERÊNCIA PREPARATORIA DO MERCIO E EMPREGO EM GENEBRA, SUÍÇA. CONFERÊNCIA } \\
\text { DA ENERGIA EM HAIA, HOLANDA. }\end{array}$ \\
\hline FILIAÇÃO PARTIDÁRIA: \\
\hline PARENTESCO: FILHO DE OTÁVIO AUGUSTO DE PAIVA TEIXEIRA E DE CELINA SOARES DE PAIVA. ERA \\
\hline CASADO COM EDITE FELICIANO DE PAIVA, COM QUEM TEVE QUATRO FILHOS. \\
\hline
\end{tabular}


4 - DIRETOR: LUCAS LOPES

PRESIDENTE: JUSCELINO KUBITSCHEKI

PERÍODO DA HISTÓRIA: DESENVOLVIMENTISMO

GESTÃO: FEVEREIRO DE 1956 - JUNHO 1958

LOCAL E DATA DE NASCIMENTO: 25/06/1911 - OURO PRETO

LOCAL E DATA DE MORTE: 29/01/1994 - RIO DE JANEIRO

FORMAÇÃO/PROFISSÃO: ENGENHEIRO CIVIL E POLÍTICO BRASILEIRO

CARREIRA: ENGENHEIRO CIVIL E ECONOMISTA E PROFESSOR DE GEOGRAFIA ECONÔMICA NA UNIVERSIDADE DE MINAS GERAIS. SECRETÁRIO DE VIAÇÃO E OBRAS PÚBLICAS DE MINAS GERAIS. MINISTRO DE VIAÇÃO E OBRAS PÚBLICAS. COORDENADOR DO PROGRAMA DE ESTABILIZAÇÃO MONETÁRIA. DOUTOR HONORIS CAUSA DO DIPLOMA " DOCTOR OF LAWS" NEW YORK UNIVERSITY, UNIVERSIDADE DE OURO PRETO E PELA ESCOLA SUPERIOR DE GUERRA

FILIAÇÃO PARTIDÁRIA:

PARENTESCO: seu filho FRANCISCO LOPES foi presidente do Banco Central no segundo governo Fernando Henrique Cardoso

FILHO DE FRANCISCO ANTÔNIO LOPES E DE MARIA DA CONCEIÇÃO MOSQUEIRA LOPES. CASOU-SE COM ESTER DE PÁDUA LOPES, COM QUEM TEVE TRÊS FILHOS 
5 - DIRETOR: ROBERTO DE OLIVEIRA CAMPOS

PRESIDENTE: JUSCELINO KUBITSCHEK

PERÍODO DA HISTÓRIA: DESENVOLVIMENTISMO

GESTÃO: AGOSTO DE 1958 - JULHO DE 1959

LOCAL E DATA DE NASCIMENTO: 17/04/1917 - CUIABÁ -MATO GROSSO

LOCAL E DATA DE MORTE: 09/10/2001 - RIO DE JANEIRO

FORMAÇÃO/PROFISSÃO: ECONOMISTA DIPLOMATA E POLÍTICO

CARREIRA: DEPUTADO FEDERAL, SENADOR E MINISTRO DO PLANEJAMENTO NO GOVERNO CASTELLO BRANCO

FILIAÇÃO PARTIDÁRIA:SENADOR PELO PARTIDO DEMOCRÁTICO SOCIAL (PDS, SUCESSOR DO PARTIDO ARENA) DEPUTADO FEDERAL DO RIO DE JANEIRO PELO PARTIDO PROGRESSISTA BRASILEIRO. MINISTRO DAS RELAÇÕES EXTERIORES EM VÁRIOS GOVERNOS COMEÇANDO POR GETÚLIO PASSANDO POR CASTELLO E COLLOR. PROJETOS IDEALIZADOS COMO FMI, BIRD, BNDES, BNH,

PARENTESCO: FILHO DE VALDOMIRO DE OLIVEIRA CAMPOS E HONORINA DE OLIVEIRA CAMPOS. CASOUSE COM MARIA ESTELA TAMBELINNI DE OLIVEIRA CAMPOS, COM QUEM TEVE TRÊS FILHOS 
PRESIDENTE: JUSCELINO KUBITSCHEK

PERÍODO DA HISTÓRIA: DESENVOLVIMENTISMO

GESTÃO: JULHO 1959 - FEVEREIRO DE 1961

LOCAL E DATA DE NASCIMENTO: 03/03/1907 - RIO DE JANEIRO

LOCAL E DATA DE MORTE: 24/12/1991 -

FORMAÇÃO/PROFISSÃO:MILITAR, ENGENHEIRO E ADMINISTRADOR BRASILEIRO

CARREIRA:INTERVENTOR FEDERAL NO RIO DE JANEIRO. CAPITÃO DE FRAGATA.COMANDANTE DOS

MARINHEIROS. SUB CHEFE GABINETE MILITAR. COMISSÃO DE DESENVOLVIMENTO INDUSTRIAL. GRUPO

EXECUTIVO DA INDUSTRIA AUTOMIBILISTICA (GEIA). COMPANHIA SIDERURGICA NACIONAL(CSN).

GRUPO EXECUTIVO DA INDUSTRIA DA CONSTRUÇÃO NAVAL (GEICON)

FILIAÇÃO PARTIDÁRIA: PRP

PARENTESCO: FILHO DE BERNARDO MARTINS MEIRA E DE ISABEL DE SOUSA MEIRA. ERA CASADO COM HELENA CELSO MEIRA, COM QUEM TEVE UMA FILHA. 


\begin{tabular}{|c|}
\hline 7 - DIRETOR: JOSE VICENTE DE FARIA LIMA \\
\hline PRESIDENTE: JANIO QUADROS \\
\hline PERÍODO DA HISTÓRIA: DEMOCRACIA \\
\hline GESTÃO: FEVEREIRO DE 1961 - SETEMBRO DE 1961 \\
\hline LOCAL E DATA DE NASCIMENTO: 07/10/1909 - RJ \\
\hline LOCAL E DATA DE MORTE: 04/10/1969 - RJ \\
\hline FORMAÇÃO/PROFISSÃO: ENGENHARIA AERONAUTICA \\
\hline \multirow{3}{*}{$\begin{array}{l}\text { CARREIRA: BRIGADEIRO DA AERONAUTICA. CORREIO AÉREO NACIONAL. MINISTÉRIO DA AERONAUTICA. } \\
\text { ASSISTENTE CHEFE COMISSÃO DA AERONAUTICA TÉCNICO NOS ESTADOS UNIDOS. PRESIDENTE DA } \\
\text { VASP. SECRETÁRIO DE VIAÇÃO DE OBRAS PÚBLICAS. PREFEITO DE SÃO PAULO }\end{array}$} \\
\hline \\
\hline \\
\hline FILIAÇÃO PARTIDÁRIA: ARENA \\
\hline \begin{tabular}{|l} 
PARENTESCO: \\
FILHO DE JOÃO SOARES LIMA, IMIGRANTE PORTUGUÊS QUE TRABALHAVA NO ARSENAL
\end{tabular} \\
\hline DE MARINHA, E DE CASTORINA FARIA LIMA. UM DE SEUS IRMÃOS, O ALMIRANTE FLORIANO PEIXOTO \\
\hline FARIA LIMA, FILIADO A ARENA , FOI PRESIDENTE DA PETROBRAS DE 1973 A 1974 E GOVERNADOR DO \\
\hline ESTADO DO RIO DE JANEIRO DE 1975 A 1979. OUTRO IRMÃO, O BRIGADEIRO ROBERTO FARIA LIMA, FOI \\
\hline INSPETOR-GERAL DA AERONÁUTICA EM 1974. FOI CASADO COM IOLANDA FARIA LIMA, PRIMA DO \\
\hline GENERAL SIZENO SARMENTO, INTERVENTOR FEDERAL NO AMAZONAS ENTRE 1946 E 1947, COMANDANTE \\
\hline DO II EXÉRCITO ENTRE 1967 E 1968 E DO I EXÉRCITO DE 1968 A 1971. TEVE TRÊS FILHOS. SEU \\
\hline SOBRINHO JOSÉ ROBERTO FARIA LIMA FOI DEPUTADO FEDERAL POR SÃO PAULO DE 1971 A 1979. \\
\hline
\end{tabular}


PRESIDENTE: JOÃO GOULART

PERÍODO DA HISTÓRIA: DEMOCRACIA

GESTÃO: SETEMBRO DE 1961 - JUNHO DE 1963

LOCAL E DATA DE NASCIMENTO: 02/11/1915 ALEGRETE - RIO GRANDE DO SUL

LOCAL E DATA DE MORTE: 12/07/1999 - PORTO ALEGRE (RS)

FORMAÇÃO/PROFISSÃO:ADVOGADO E ECONOMISTA

CARREIRA: GUARDA LIVROS NA COOPERATIVA DOS FUNCIONARIOS DA VIAÇÃO FÉRREA DO RIO GRANDE DO SUL. ESCRITURÁRIO DA LIMA E SILVA S/A EXPORTADORA. PROFESSOR DO COLÉGIO BATISTA AMERICANO. MILITANTE DA USB- UNIÃO SOCIAL BRASILEIRA. DEPUTADO ESTADUAL NO RIO GRANDE DO SUL. SECRETÁRIO NA CAMPANHA DE PASQUALINI AO GOVERNO. FUNDADOR DO MDB. SECRETÁRIO ESTADUAL DE ECONOMIA (POR LEONEL BRIZOLA). MINISTRO PLENPOLENCIANO E CHEFE DA DELEGAÇÃO BRASILEIRA À ASSOCIAÇÃO LATINO AMERICANA DE LIVRE COMÉRCIO ( ALALC) E SEU EMBAIXADOR.

FILIAÇÃO PARTIDÁRIA: PTB

PARENTESCO: FILHO DE AFONSO ANTUNES DA SILVA E DE FRANCISCA DE ALMEIDA ANTUNES.CASADO COM JULIETA DE LIMA E SILVA ANTUNES, TEVE QUATRO FILHOS. 


\begin{tabular}{|c|}
\hline 9 - DIRETOR: JOSÉ GARRIDO TORRES \\
\hline PRESIDENTE: HUMBERTO DE ALENCAR CASTELLO BRANCO \\
\hline PERÍODO DA HISTÓRIA: REGIME MILITAR \\
\hline GESTÃO: JULHO 1964 - MARÇO 1967 \\
\hline LOCAL E DATA DE NASCIMENTO: 13/01/1915 - RJ \\
\hline LOCAL E DATA DE MORTE: 06/09/1974 - RJ \\
\hline FORMAÇÃO/PROFISSÃO: ECONOMISTA \\
\hline $\begin{array}{l}\text { CARREIRA: MEMBRO DA CNE - CONSELHO NACIONAL DE ECONOMIA. DELEGADO DA CEPAL. PRESIDENTE } \\
\text { DA CONSELHO NACIONAL DE ECONOMIA ( CNE) NOMEADO POR JUSCELINO KUBITSCHEK. SUPLENTE DA } \\
\text { OEA. GOVERNADOR SUPLENTE DO BRASIL NO FMI - FUNDO MONETÁRIO } \\
\text { INTERNACIONAL.SUPERINTENDENTE DA MOEDA E DO CRÉDITO MEMBRO DA CONSULTEC - PLANO DE } \\
\text { ESTABILIZAÇÃO MONETÁRIA. CONSULTOR DO BIC. DIRETOR DA FUNDAÇÃO GETÚLIO VARGAS. VICE- } \\
\text { REITOR DA PUC/RJ, DIRETOR DA ACP - ASSOCIAÇÃO DE PECULIOS DOS EXECUTIVOS. MEMBRO DA } \\
\text { ROYAL ECONOMICS SOCIETY LONDRES. AMERICAN ECONOMIC ASSOCIATION E CATHOLIC ECONOMIC } \\
\text { ASSOCIATION - EUA. }\end{array}$ \\
\hline FILIAÇÃO PARTIDÁRIA: \\
\hline $\begin{array}{l}\text { PARENTESCO: FILHO DE JOSÉ GARRIDO TORRES E OLGA COELHO TORRES. ERA CASADO COM LUCÍLIA } \\
\text { VIEIRA GARRIDO TORRES, COM OUEM TEVE TRÊS FILHOS. }\end{array}$ \\
\hline
\end{tabular}




\section{0 - DIRETOR: JAIME MAGRASSI SÁ}

PRESIDENTE: COSTA E SILVA

PERÍODO DA HISTÓRIA: REGIME MILITAR

GESTÃO: MARÇO 1967 - OUTUBRO 1970

LOCAL E DATA DE NASCIMENTO: 14/03/1921 - PORTO ALEGRE/RS

LOCAL E DATA DE MORTE:

FORMAÇÃO/PROFISSÃO: CONTADOR E ECONOMISTA

CARREIRA: PROFESSOR NA FACULDADE DE CIÊNCIAS ECONÔMICAS DO ESTADO DA GUANABARA. TECNICO EM ECONOMIA DO CONSELHO DE DESENVOLVIMENTO DO BANCO CENTRAL. ASSESSOR TÉCNICO DA COMISSÃO FEDERAL DE ABASTECIMENTO E PREÇÇOS - COFAP. CHEFE DE GABINETE DO DIRETOR SUPERINTENDENTE DO BNDE. ECONOMISTA SUMOC. CHEFE DA AUDITORIA INTERNA DO BNDE. REDATOR DA REVISTA DESENVOLVIMENTO E CONJUNTURA. COMISSÃO BNDE PARA TOMADA DE PREÇOS. MEMBRO DA DELEGAÇÃO À CONFERÊNCIA DO GATT. ASSESSOR PARA ASSUNTOS RELACIONADOS A ALIANÇA PARA O PROGRESSO. CHEFE DO DEPARTAMENTO FINANCEIRO DO BNDE. COLUNA NO JORNAL DO BRASIL "COMENTÁRIO ECONÔMICO". CONSELHO DA DELEGAÇÃO BRASILEIRA AS REUNIÕES ANUAIS DO CONSELHO INTERAMERICANO E SOCIAL EM SÃO PAULO. PROFESSOR DA PUC /RJ. DIRETOR DO FUNDO DE FINANCIAMENTO DE PESQUISA DA PEQUENA E MÉDIA EMPRESA - FIPEME. PRESIDENTE FINAME, ALALC, IBGE. MEMBRO DO CONSELHO CONSULTIVO DAS ESTATAIS USIMINAS, COSIPA, CSN.

FILIAÇÃO PARTIDÁRIA:

PARENTESCO: FILHO DO COMERCIANTE E INDUSTRIAL ANTÔNIO DE SÁ E DE IRMA MAGRASSI DE SÁ. CASADO COM ADILES MARTINS COSTA DE SÁ, TEVE UMA FILHA. 


\begin{tabular}{|c|}
\hline 11 - DIRETOR: MARCOS PEREIRA VIANNA \\
\hline PRESIDENTE: EMÍLIO GARRASTAZU MÉDICE E ERNESTO GEISEL \\
\hline PERÍODO DA HISTÓRIA: REGIME MILITAR \\
\hline GESTÃO: OUTUBRO DE 1970 - MARÇO DE 1974 / MARÇO 1974 - MARÇO 1979 \\
\hline LOCAL E DATA DE NASCIMENTO: 08/05/1934 -VITÓRIA \\
\hline LOCAL E DATA DE MORTE: 26/06/2012 - \\
\hline FORMAÇÃO/PROFISSÃO: ENGENHEIRO \\
\hline $\begin{array}{l}\text { CARREIRA:SECRETÁRIO EXECUTIVO DO MINISTÉRIO DO PLANEJAMENTO. NA PRESIDENCIA DO BNDE } \\
\text { CUMPRIU O II PND. SUPERINTENDENTE GERAL DA CIA VALE DO RIO DOCE. DIRETOR BENITA - } \\
\text { BENEFICIAMENTO DE ITABIRITOS S/A AÇOS ANHANGUERA E RIO DOCE MADEIRAS. PRESIDENTE IPHAN, } \\
\text { FINAME. SUPERINTENDENTE IPEA. PRESIDENTE DO IPLAN, TECNICORP DTVM. DIRETOR DA CACEX. }\end{array}$ \\
\hline FILIAÇÃO PARTIDÁRIA: ARENA \\
\hline PARENTESCO: FILHO DE ARI VIANA E DE MARIA MADALENA PEREIRA VIANA. CASOU-SE PELA PRIMEIRA \\
\hline $\begin{array}{l}\text { VEZ COM DAISY VIANNA, COM QUEM TEVE TRÊS FILHOS, UNINDO-SE MAIS TARDE A ARIANE CASTELO DA } \\
\text { COSTA. }\end{array}$ \\
\hline
\end{tabular}


PRESIDENTE: JOÃO BAPTISTA FIGUEIREDO

PERÍODO DA HISTÓRIA: REGIME MILITAR

GESTÃO: MARÇO DE 1979 - SETEMBRO DE 1983

LOCAL E DATA DE NASCIMENTO: 09/12/1933 - NAZARÉ ( BA)

LOCAL E DATA DE MORTE: 16/05/1995 -SALVADOR

FORMAÇÃO/PROFISSÃO: ADVOGADO E ADMINISTRADOR

CARREIRA: PROFESSOR NA ESCOLA DE ADMINISTRAÇÃO DA UFBA E PUC/BA. DIRETOR DA FIEP/BA E BNH. SECRETÁRIO DA FAZENDA. PRESIDENTE DO BANCO DO ESTADO DA BAHIA. REPRESENTANTE DO MINISTÉRIO DO INTERIOR NA COMISSÃO NACIONAL DA INDÚSTRIA DA CONSTRUÇÃO CIVIL E NO CONSELHO NACIONAL DE POLÍTICA DE EMPREGO. DIRETOR DA ABNT.

FILIAÇÃO PARTIDÁRIA:

PARENTESCO: FILHO DE ARISTIDES CARMELO GOMES DE OLIVEIRA E DE ALZIRA DE CALDAS BRITO SANDE E OLIVEIRA. ERA CASADO COM MÍRIAM FREIRE SANDE E OLIVEIRA, COM QUEM TEVE CINCO FILHOS. 
PRESIDENTE: JOÃO BAPTISTA FIGUEIREDO

PERÍODO DA HISTÓRIA: REGIME MILITAR

GESTÃO: SETEMBRO 1983 - OUTUBRO DE 1984

LOCAL E DATA DE NASCIMENTO: 27/04/1942 - SALVADOR

LOCAL E DATA DE MORTE:

FORMAÇÃO/PROFISSÃO: ADMINISTRADOR - UFBA

CARREIRA: ASSESSOR CHEFE SECRETARIA DA FAZENDA DA BAHIA NO GOVERNO DE ANTONIO CARLOS MAGALHÃES. PRESIDENTE DA COMISSÃO DE INTEGRAÇÃO DO SISTEMA FINANCEIRO DE FLORIANO PEIXOTO FARIA LIMA. DIRETOR FINANCEIRO FURNAS - CENTRAIS ELÉTRICAS S/A. DIRETOR DO INSTITUTO BRASILEIRO DE EXECUTIVOS FINANCEIROS - IBEF/ RJ. PRESIDENTE DO DESENBANCO BANCO DE DESENVOLVIMENTO DO ESTADO DA BAHIA. MEMBRO DO CONSELHO DE ADMINISTRAÇÃO DE EMPRESAS DE DESENVOLVIMENTO URBANO. PRESIDENTE DA PROPAR - PROMOÇÕES E PARTICIPAÇÕES DA BAHIA. COMISSÃO CONSULTIVA DO MERCAO DE CAPITAIS DO CONSELHO MONETÁRIO NACIONAL. VICE- PRESIDENTE FINAME. SUDENE. CONSELHO DE TECNOLOGIA INDUSTRIAL DA SECRETARIA DE TECNOLOGIA DO MINISTÉRIO DA INDÚSTRIA E COMÉRCIO. DIRETOR DO BANCO ECONÔMICO S/A. FILIAÇÃO PARTIDÁRIA:

PARENTESCO: FILHO DE JAIME SAMPAIO FREIRE E CRISANTEMA LINS FREIRE. CASOU-SE COM ELCI SANTOS FREIRE, COM QUEM TEVE UM FILHO. 


\begin{tabular}{|c|}
\hline 14 - DIRETOR: JOSÉ CARLOS PERDIGÃO MEDEIROS DA FONSECA \\
\hline PRESIDENTE: JOÃO BAPTISTA FIGUEIREDO \\
\hline PERÍODO DA HISTÓRIA: REGIME MILITAR \\
\hline GESTÃO: OUTUBRO 1984 - MARÇO 1985 \\
\hline LOCAL E DATA DE NASCIMENTO: $13 / 11 / 1925$ - RIO DE JANEIRO \\
\hline LOCAL E DATA DE MORTE: \\
\hline FORMAÇÃO/PROFISSÃO: ADVOGADO - UFRJ \\
\hline $\begin{array}{l}\text { CARREIRA: CHEFE DO DEPARTAMENTO JURÍDICO DA PÁTRIA. SUPERINTENDENTE DA MOEDA E DO } \\
\text { CRÉDITO - SUMOC/BB. CHEFE JURÍDICO ASSESSOR DO GABINETE CIVIL DA PRESIDÊNCIA DA REPÚBLICA. } \\
\text { ASSISTENTE TÉCNICO DA CPI SOBRE LIGAS CAMPONESAS. ELEBORAÇÃO DA LEI DA REFORMA BANCÁRIA } \\
\text { No } 4595 \text { DE 31/12/1964. ADVOGADO DO BANCO CENTRAL. DIRETOR EXECUTIVO DO BID. PRESIDENTE } \\
\text { BNDESPAR, FINAME, SUDENE, SIDERBRAS, COBRA (COMPUTADORES E SISTEMAS BRASILEIROS S/A). }\end{array}$ \\
\hline FILIAÇÃO PARTIDÁRIA: \\
\hline PARENTESCO FILHO DE ARNOLDO MEDEIROS DA FONSECA E DE MARIA LUÍSA PERDIGÃO DA F \\
\hline FOI CASADO COM MARIA BEATRIZ RIBEIRO MEDEIROS DA FONSECA E TEVE UMA FILH \\
\hline
\end{tabular}


PRESIDENTE: JOSÉ SARNEY

PERÍODO DA HISTÓRIA: ABERTURA POLÍTICA REGIME DEMOCRÁTICO

GESTÃO: MARÇO DE 1985 - AGOSTO DE 1985

LOCAL E DATA DE NASCIMENTO: 23/10/1933 - SÃO PAULO

LOCAL E DATA DE MORTE: 12/04/1989 - SÃO PAULO

FORMAÇÃO/PROFISSÃO: EMPRESÁRIO E POLÍTICO

CARREIRA: DIRETOR DO CENTRO DAS INDÚSTRIAS DO ESTADO DE SÃO PAULO - CIESP; DIRETOR DO DEPARTAMENTO DE COMÉRCIO EXTERIOR - FIESP; MEMBRO DO DO CONSELHO DE COMÉRCIO EXTERIOR - CNI; MEMBRO DO CONSELHO DE ASSUNTOS LEGISLATIVO DA CNI; DIRETOR DO DEPARTAMENTO DE ESTATÍSTICA DA FIESP; DIRETOR ADJUNTO DO DEPARTAMENTO DE ECONOMIA DA FIESP; CONSELHEIRO ESPECIAL DA CNI; PRESIDENTE DA ASSOCIAÇÃO BRASILEIRA DE PLÁSTICO; PRESIDENTE DA ASSOCIAÇÃO LATINO AMERICANA DE PLÁSTICOS; PRESIDENTE DO SINDICATO DA INDUSTRIA DE MATERIAL PLÁSTICO; VICE-PRESIDENTE DA FIESP;MEMBRO DO CONSELHO DE COMÉRCIO EXTERIOR DA FIESP; CONSELHEIRO DA ESCOLA DE ADMINISTRAÇÃO DE EMPRESAS DA FUNDAÇÃO GETÚLIO VARGAS; PRESIDENTE DO CONSELHO DE TECNOLOGIA DO ESTADO DE SÃO PAULO; SECRETÁRIO DA ECONOMIA E PLANEJAMENTO DO ESTADO DE SÃO PAULO (GOVERNO ABREU SODRÉ); SECRETÁRIO DA FAZENDA DO ESTADO DE SÃO PAULO (GOVERNO ABREU SODRÉ); MEMBRO DO CONSELHO DE ECONOMIA DA FIESP;MEMBRO DO CONSELHO DA FUNDAÇÃO PADRE ANCHIETA (TV EDUCATIVA); PRESIDENTE DO CONSELHO DA VASP.

FILIAÇÃO PARTIDÁRIA: PMDB

PARENTESCO: FILHO DO IMIGRANTE ITALIANO PASCOAL FUNARO E DE HELENA KRALJEVIC FUNARO. SUA IRMÃ DALVA FUNARO CASOU-SE COM O EMPRESÁRIO FERNANDO GASPARIAN, MAIS TARDE CONSTITUINTE (1987-1988) E DEPUTADO FEDERAL POR SÃO PAULO ENTRE 1987 E 1991. ERA CASADO COM ANA MARIA SUPLICY FUNARO, IRMÃ DE EDUARDO MATARAZZO SUPLICY, DEPUTADO FEDERAL POR SÃO PAULO ENTRE 1983 E 1987, VEREADOR À CÂMARA MUNICIPAL DE SÃO PAULO ENTRE $1989 \mathrm{E} 1991 \mathrm{E}$ SENADOR POR SÃO PAULO A PARTIR DE 1991. TEVE SEIS FILHOS. DEIXOU GRAVADA EM FITAS DE VÍDEO A PRIMEIRA VERSÃO DE UM LIVRO EM QUE CONTA OS BASTIDORES DA NEGOCIAÇÃO DA DÍVIDA EXTERNA E MOMENTOS QUE PASSOU AO DECRETAR A MORATÓRIA EM FEVEREIRO DE 1987 
PRESIDENTE: JOSÉ SARNEY

PERÍODO DA HISTÓRIA: DEMOCRACIA

GESTÃO: AGOSTO 1985 - JANEIRO 1987

LOCAL E DATA DE NASCIMENTO: 24/02/1944 - SÃO PAULO

LOCAL E DATA DE MORTE:

FORMAÇÃO/PROFISSÃO: ECONOMISTA

CARREIRA: PROFESSOR TITULAR DA UNIVERSIDADE DE SÃO PAULO - FACULDADE DE ECONOMIA, ADMINISTRAÇÃO E CONTABILIDADE DA UNIVERSIDADE DE SÃO PAULO. DOUTOR EM ECONOMIA UNIVERSIDADE YALE, ESTADOS UNIDOS (1975). ECONOMISTA FORMADO PELA FACULDADE DE ECONOMIA, ADMINISTRAÇÃO E CONTABILIDADE (FEA/USP) (TURMA DE 1965). SECRETÁRIO DE ESTADO DE ECONOMIA E PLANEJAMENTO - GOVERNO DO ESTADO DE SÃO PAULO (1995/2002). PRESIDENTE DA COMISSÃO DIRETORA DO PROGRAMA NACIONAL DE DESESTATIZAÇÃO (1993/1994). VICE-DIRETOR DA FACULDADE DE ECONOMIA DA USP (1990/1994). PRESIDENTE DA FUNDAÇÃO INSTITUTO DE PESQUISAS ECONÔMICAS (FIPE) (1989/1993). PRESIDENTE DO BANCO NACIONAL DE DESENVOLVIMENTO ECONÔMICO E SOCIAL (BNDES) (1985/1988). CANDIDATO AO CARGO DE DEPUTADO FEDERAL PELO PSDB EM 2002 - OBTEVE 65.685 VOTOS. FOI DEPUTADO FEDERAL SUPLENTE TENDO SIDO EFETIVADO EM 2011

FILIAÇÃO PARTIDÁRIA: PSDB

PARENTESCO: FILHO DE ANDRÉ FRANCO MONTORO E LUCI PESTANA SILVA FRANCO MONTORO. SEU PAI FOI DEPUTADO FEDERAL (1959-1961, 1962-1971, 1995-1999), MINISTRO DO TRABALHO (1961-1962), SENADOR (1971-1983) E GOVERNADOR DE SÃO PAULO (1983-1987). CASOU-SE COM GILDA MARIA CASTANHO FRANCO MONTORO, COM QUEM TEVE QUATRO FILHOS. 
17 - DIRETOR: MARCIO FORTES

PRESIDENTE: JOSÉ SARNEY

PERÍODO DA HISTÓRIA: DEMOCRACIA

GESTÃO: JANEIRO 1987 - SETEMBRO 1989

LOCAL E DATA DE NASCIMENTO: 04/10/1944 BELO HORIZONTE

LOCAL E DATA DE MORTE:

FORMAÇÃO/PROFISSÃO: ENGENHEIRO CIVIL EMPRESÁRIO E POLÍTICO

CARREIRA: PRESIDENTE ADEMI/RJ. CONSELHO FGV E PUC. PROMOTOR DO FORUM NACIONAL IBEF. PRESIDENTE INAE - INSTITUTO NACIONAL DE ALTOS ESTUDOS. DIRETOR NO BRASIL DA ONU DESENVOLVIMENTO SUSTENTÁVEL. PRESIDENTE BANERG. MINISTRO INTERINO DA FAZENDA. SECRETÁRIO GERAL MF. SECRETÁRIO MUNICIPAL DE OBRAS. DEPUTADO FEDERAL - RJ. SECRETARIA ESTADUAL DE INSUSTRIA COMERCIO E TURISMO. VICE-PRESIDENTE DO PSDB. VICE-PRESIDENTE FIRJAN - FEDERAÇÃO DAS INDÚSTRIAS DO RIO DE JANEIRO.CPMF - COMISSÃO DE REFORMA TRIBUTÁRIA.

FILIAÇÃO PARTIDÁRIA: PSDB/RJ

PARENTESCO: FILHO DE JOÃO MACHADO FORTES E DA PROFESSORA MARIA AUGUSTA DE ANDRADE FORTES. SEU PAI, ALÉM DE PRESIDENTE DO GRUPO JOÃO FORTES ENGENHARIA, ERA MILITAR, CONTEMPORÂNEO DO GENERAL E EX-PRESIDENTE DA REPÚBLICA JOÃO BATISTA FIGUEIREDO (19791985). CASOU-SE COM CÉLIA MARIA CORREIA FORTES, COM QUEM TEVE TRÊS FILHOS. 
18 - DIRETOR: NEI FONTES DE MELO TÁVORA

PRESIDENTE: JOSÉ SARNEY

PERÍODO DA HISTÓRIA: DEMOCRACIA

GESTÃO: OUTUBRO 1989 - MARÇO 1990

LOCAL E DATA DE NASCIMENTO: 09/03/1947 - SALVADOR

LOCAL E DATA DE MORTE:

FORMAÇÃO/PROFISSÃO: ENGENHEIRO CIVIL - PUC/RJ

CARREIRA: AUXILIAR TÉCNICO GEIPOT MINISTÉRIO DOS TRANSPORTES. DIRETOR TÉCNICO DA SERVIÇOS ASSESSORIA E PLANEJAMENTO E ENGENHARIA S/A. DIRETOR MAGRUP ENGENHARIA LTDA. PRIMEIRO CARGO PÚBLICO BNDES PREOCUPADO COM PROJETOS SOCIAIS. DIRETOR PRESIDENTE DA MELO TÁVORA ENGENHARIA LTDA. DIRETOR PORTO REAL.

FILIAÇÃO PARTIDÁRIA:

PARENTESCO : FILHO DE JOSÉ EDILSON DE MELO TÁVORA E DE LÚCIA MARIA DE FONTES TÁVORA. SEU PAI FOI DEPUTADO FEDERAL PELO CEARÁ ENTRE 1959 E 1975. CASADO COM ANA LUÍSA DE MELO TÁVORA, TEVE DOIS FILHOS. 
PRESIDENTE: FERNANDO COLLOR DE MELLO

PERÍODO DA HISTÓRIA: DEMOCRACIA

GESTÃO: MARÇO 1990 - OUTUBRO 1993

LOCAL E DATA DE NASCIMENTO: 20/06/1952

LOCAL E DATA DE MORTE:

FORMAÇÃO/PROFISSÃO:

1970 - ENGENHEIRO PUC/RJ PARALELAMENTE.

1971 /1972 -ADMINISTRAÇÃO PÚBLICA NA FG V/RJ.

1973 -ENGENHARIA DE SISTEMAS

1974 - EM ECONOMIA PELA FACULDADE DE CIÊNCIAS POLÍTICAS E ECONÔMICAS/RJ.

1974 E/1978 - MESTRADO EM ADMINISTRAÇÃO, FINANÇAS E SISTEMAS DE INFORMAÇÃO NA ALFRED P. SLOAN SCHOOL OF MANAGEMENT, DO MASSACHUSETTS INSTITUTE OF TECHNOLOGY (MIT), EM CAMBRIDGE (EUA), COM UMA BOLSA DE ESTUDOS DA ORGANIZAÇÃO DOS ESTADOS AMERICANOS (OEA), ENTRE.

1976 E 1978. FEZ DOUTORADO EM PESQUISA OPERACIONAL E ECONOMIA NAQUELA MESMA INSTITUIÇÃO EM SUA TESE DESENVOLVEU UM MODELO PARA AVALIAR AS ALTERNATIVAS ENERGÉTICAS RENOVÁVEIS.

CARREIRA:

1978/1979 - FOI PROFESSOR VISITANTE NA ALFRED P. SLOAN SCHOOL OF MANAGEMENT 1982 - CONSULTOR DA COMPANHIA VALE DO RIO DOCE, NO RIO DE JANEIRO.

1985/1986 -I DIRETOR DA MACROMÉTRICA PESQUISAS ECONÔMICAS E DA CONSULTORIA DE ANÁLISE E PROJEÇÕES ECONÔMICAS- RJ. NO FINAL DO MESMO ANO FOI CHAMADO A PARTICIPAR DAS DISCUSSÕES DO PLANO CRUZADO ( "TABLITA"), QUE RETIRAVA DAS DÍVIDAS A PREVISÃO INFLACIONÁRIA EMBUTIDA. AINDA NO GOVERNO SARNEY, PARTICIPOU DAS DISCUSSÕES QUE CULMINARAM NUM OUTRO PLANO ECONÔMICO, O PLANO BRESSER, TENDO SIDO O RESPONSÁVEL DIRETO PELO DESENVOLVIMENTO DE UMA NOVA FERRAMENTA ECONÔMICA: A UNIDADE DE REFERÊNCIA DE PREÇOS (URP). A IDÉIA DESTE MODELO DE INDEXAÇÃO ERA PERMITIR QUE O ACÚMULO INFLACIONÁRIO NÃO FOSSE REPASSADO RAPIDAMENTE PARA OS PREÇOS E SALÁRIOS, IMPEDINDO ASSIM UMA RÁPIDA PROPAGAÇÃO DA INFLAÇÃO. NO ENTANTO, SUA IDÉIA ORIGINAL FOI ALTERADA, FATO QUE NÃO LHE AGRADOU MUITO E QUE FEZ COM QUE DECLARASSE: "A URP É MINHA, MAS O ARROCHO SALARIAL É DO BRESSER." 1986 - TORNOU-SE DIRETOR-PRESIDENTE DA ECONOTHEC CONSULTORIA, NO RIO DE JANEIRO, ONDE PERMANECERIA ATÉ 1994.

1987/1990 DIRETOR DO DEPARTAMENTO DE ECONOMIA DA PUC-RIO. PARALELAMENTE FOI ECONOMISTA-CHEFE DO BANCO STERLING, NO RIO DE JANEIRO,.

1990 - DIAS DEPOIS DA POSSE DE FERNANDO COLLOR DE MELO NA PRESIDÊNCIA DA REPÚBLICA, SUBSTITUIU NEI TÁVORA À FRENTE DO BANCO NACIONAL DO DESENVOLVIMENTO ECONÔMICO E SOCIAL (BNDES). UM DOS PRINCIPAIS FORMULADORES DO PLANO COLLOR, FEZ PARTE DA EQUIPE ECONÔMICA LIDERADA PELA ECONOMISTA ZÉLIA CARDOSO DE MELO QUE PROJETOU A POLÍTICA ANTIINFLACIONÁRIA QUE CONFISCOU AS CADERNETAS DE 
POUPANÇA E APLICAÇÕES FINANCEIRAS DE 80\% DAS EMPRESAS E CIDADÃOS BRASILEIROS, ALÉM DE ABRIR AS PORTAS DO PAÍS ÀS IMPORTAÇÕES. FOI INDICADO POR COLLOR EM MAIO DE 1990 PARA PRESIDIR A COMISSÃO DIRETORA DO PROGRAMA NACIONAL DE DESESTATIZAÇÃO, QUE INICIOU O PROCESSO DE PRIVATIZAÇÃO DAS EMPRESAS ESTATAIS E PREVIA, PARA A COMPRA DESTAS, A ABERTURA AO CAPITAL ESTRANGEIRO E TRÊS FORMAS DE PAGAMENTO: A UTILIZAÇÃO DOS CRUZADOS NOVOS RETIDOS PELO BANCO CENTRAL, CERTIFICADOS DE PRIVATIZAÇÃO E A CONVERSÃO DA DÍVIDA EXTERNA EM INVESTIMENTO. PERMANECEU À FRENTE DA COMISSÃO DIRETORA ATÉ SUA SAÍDA DO BNDES.

1992 - LOGO APÓS O IMPEACHMENTDO PRESIDENTE FERNANDO COLLOR, PEDIU DEMISSÃO DA PRESIDÊNCIA DO BNDES, SENDO SUBSTITUÍDO POR ANTÔNIO BARROS DE CASTRO.

1993 - VICE-PRESIDENTE DE INVESTIMENTOS DO BANCO ITAMARATI S.A (EM 1997 COMPRADO PELO BRADESCO).

- VICE-PRESIDENTE DE INVESTIMENTOS DO BANCO CREFISUL S.A., LIQUIDADO EXTRAJUDICIALMENTE PELO BANCO CENTRAL 1994 - PRESIDENTE DO CONSELHO DE ADMINISTRAÇÃO DO GRUPO MODIANO, NO RIO DE JANEIRO.

- CONSULTOR DO BANCO FONTE-CINDAM, CUJO PRESIDENTE DESDE 1993 ERA LUIZ ANTÔNIO GONÇALVES, ASSOCIADO A FERNANDO CÉSAR DE CARVALHO, FUNDADOR DO BANCO FONTE, E A ROBERTO STEINFELD, NO QUAL MODIANO TINHA PARTICIPAÇÃO. PERMANECEU NO BANCO ATÉ MAIO DE 1999, QUANDO GONÇALVES FOI ACUSADO DE CRIME CONTRA O SISTEMA FINANCEIRO POR FIRMAR EMPRÉSTIMOS MÚTUOS ENTRE EMPRESAS NAS QUAIS O PRÓPRIO FONTE CINDAM TINHA PARTICIPAÇÃO.

ARROLADO NO PROCESSO, EM JUNHO DE 1999 EDUARDO MARCO MODIANO SOLICITOU SUA EXCLUSÃO, TENDO EM VISTA QUE ATUAVA NA INSTITUIÇÃO COMO ASSESSOR E CONSULTOR DE INVESTIMENTOS NA ÁREA DE FUSÃO, AQUISIÇÃO E REORGANIZAÇÃO DE EMPRESAS E EM PROCESSOS DE PRIVATIZAÇÃO. O COLEGIADO DA COMISSÃO DE VALORES MOBILIÁRIOS EM AGOSTO DO MESMO ANO ACATOU A ARGUMENTAÇÃO EXCLUINDO-O DO INQUÉRITO. DEDICA-SE A ATIVIDADES PRIVADAS À FRENTE DO GRUPO MODIANO, COM INVESTIMENTOS NA BRASIL ECODIESEL INDÚSTRIA E COMÉRCIO DE BIOCOMBUSTÍVEIS E ÓLEOS VEGETAIS S.A.

FILIAÇÃO PARTIDÁRIA:

PARENTESCO: FILHO DE UMBERTO MODIANO E LILIANE ESTER MODIANO. SEU PAI, UM FRANCÊS QUE VEIO TENTAR A SORTE NO BRASIL EM 1947, CONSTRUIU UM GRANDE PATRIMÔNIO COM A EXPORTAÇÃO DE CAFÉ. NOS ANOS 1980 PASSOU A INVESTIR NO SETOR HOTELEIRO, TENDO INSTALADO EM BÚZIOS (RJ) UM COMPLEXO TURÍSTICO COMPOSTO POR AEROPORTO, CONDOMÍNIOS E HOTÉIS. CASOU-SE COM ISABEL PARENTE DE MELO, COM QUEM TEVE TRÊS FILHAS, UNINDO-SE MAIS TARDE A MARIA CRISTINA SAMPAIO, COM QUEM TEVE UMA FILHA. 
PRESIDENTE: ITAMAR FRANCO

PERÍODO DA HISTÓRIA: DEMOCRACIA

GESTÃO: OUTUBRO 1992 - MARÇO 1993

LOCAL E DATA DE NASCIMENTO: 11/02/ 1938 - RJ

LOCAL E DATA DE MORTE: $21 / 08 / 2011$ - RJ

FORMAÇÃO/PROFISSÃO:

1959 - BACHARELOU-SE EM ECONOMIA PELA FACULDADE DE ECONOMIA E ADMINISTRAÇÃO (FEA) QUE SE TORNOU A (UFRJ).

\section{CARREIRA:}

1963 - ECONOMISTA E PESQUISADOR DO INSTITUTO LATINO-AMERICANO DE PESQUISA ECONÔMICO-SOCIAL DA COMISSÃO ECONÔMICA PARA A AMÉRICA LATINA (CEPAL), NAS NAÇÕES UNIDAS, ONDE ATUOU ATÉ 1972.

1973 - LECIONOU NA FACULDADE DE ECONOMIA DE CAMBRIDGE, NA INGLATERRA, COMO PROFESSOR-VISITANTE. EM 1974 RETORNOU AO BRASIL COMO PROFESSOR DA UNIVERSIDADE ESTADUAL DE CAMPINAS (UNICAMP).

1977 - DOUTOR PELA UNICAMP

1978 - MEMBRO DO INSTITUTE FOR ADVANCED STUDY, EM PRINCETON (EUA)

1979 - PROFESSOR DA COORDENAÇÃO DOS PROGRAMAS DE PÓS-GRADUAÇÃO DE ENGENHARIA (COPPE) DA UFRJ.

1981 - PROFESSOR TITULAR DA FEA E DO INSTITUTO DE ECONOMIA INDUSTRIAL (IEI) DA UFRJ,

1987 - EDITOR DO BOLETIM DE CONJUNTURA DO IEI/UFRJ E, EM 1989, MEMBRO DO CONSELHO DO INSTITUTO NACIONAL DE ALTOS ESTUDOS (INAE).

1990 - FOI UM CRÍTICO DESTACADO DA POLÍTICA DE ABERTURA DO COMÉRCIO EXTERIOR E DO PROGRAMA DE PRIVATIZAÇÃO EMPREENDIDOS PELO PRESIDENTE FERNANDO COLLOR DE MELO (1990-1992)

1992 - PRESIDENTE BNDES

1994 - MEMBRO DO CONSELHO DO INSTITUTO DE ESTUDOS DO DESENVOLVIMENTO INDUSTRIAL DA UFRJ 1996 MEMBRO DO CONSELHO DO SERVIÇO BRASILEIRO DE APOIO ÀS MICRO E PEQUENAS EMPRESAS (SEBRAE).

FILIAÇÃO PARTIDÁRIA:

PARENTESCO: FILHO DE EUCLIDES JOSÉ COELHO DE CASTRO E ADELINA BARROS DE CASTRO. FOI CASADO COM A ECONOMISTA E PROFESSORA UNIVERSITÁRIA ANA CÉLIA CASTRO, COM QUEM TEVE QUATRO FILHOS. 
PRESIDENTE: ITAMAR FRANCO

PERÍODO DA HISTÓRIA: DEMOCRACIA

GESTÃO: MARÇO 1993 - AGOSTO 1993

LOCAL E DATA DE NASCIMENTO: 21/10/1945 - ARARAS/SP

LOCAL E DATA DE MORTE:

FORMAÇÃO/PROFISSÃO:

1970 -FORMADO EM CIÊNCIAS ECONÔMICAS PELA PONTIFÍCIA UNIVERSIDADE CATÓLICA DE SÃO PAULO, DURANTE O CURSO

1965/1966 PRESIDIU O CENTRO TÉCNICO MACKENZIE

1967/1968 PRESIDIU O DIRETÓRIO ACADÊMICO DA FACULDADE

CARREIRA:

1970-1975 - SÓCIO-DIRETOR DA HOJE EXTINTA WASCABEL — MÁQUINAS E MATERIAIS GRÁFICOS, LOCALIZADA NO RIO DE JANEIRO. DE VOLTA A SÃO PAULO, TRABALHOU NA MANIG S.A., INDÚSTRIA VOLTADA PARA A FABRICAÇÃO DE MÁQUINAS E APARELHOS PARA A INDÚSTRIA GRÁFICA E PARA A INDÚSTRIA DE PAPEL E CARTONAGEM, PRIMEIRO COMO DIRETOR COMERCIA L

1975-1991 DIRETOR-PRESIDENTE DA MESMA.

1973 - DIRETOR DE RELAÇÕES PÚBLICAS DA ORDEM DOS ECONOMISTAS DE SÃO PAULO 1976-1979 - CHEFE DA GRÁFICA DO SINDICATO NACIONAL DA INDÚSTRIA DE MÁQUINAS (SINDIMAQ) 1977-- FUNDOU A ASSOCIAÇÃO BRASILEIRA DA INDÚSTRIA DE MÁQUINAS E EQUIPAMENTOS GRÁFICOS (ABIMEG), ONDE EXERCEU A VICE-PRESIDÊNCIA (1977-1978) E A PRESIDÊNCIA (1983-1986 E 1986-1989), O SINDIMAQ, ENTRE (1989- 1992), E O INSTITUTO DE PESQUISAS TECNOLÓGICAS (IPT), ENTRE(19901991), TAMBÉM TOMOU PARTE NO CONSELHO NACIONAL DE CIÊNCIA E TECNOLOGIA.

1991-1993 - SECRETÁRIO DE CIÊNCIA E TECNOLOGIA DO ESTADO DE SÃO PAULO, NO GOVERNO DE LUÍS ANTÔNIO FLEURY FILHO.

1993 - ASSUMIU A PRESIDÊNCIA DO BANCO NACIONAL DO DESENVOLVIMENTO ECONÔMICO E SOCIAL (BNDES). FAVORÁVEL À PRIVATIZAÇÃO DA COMPANHIA VALE DO RIO DOCE, ENTROU EM ATRITO COM O PRESIDENTE DA REPÚBLICA, ITAMAR FRANCO, E COM O MINISTRO DO PLANEJAMENTO, ALEXIS STEPANENKO, AO DENUNCIAR A OCORRÊNCIA DE IRREGULARIDADES NA CONTRATAÇÃO DE EMPRESAS DE CONSULTORIA SEM LICITAÇÃO NA ÁREA ADMINISTRATIVA DO BNDES. A SITUAÇÃO AGRAVOU-SE QUANDO DELBEN NOMEOU UMA COMISSÃO DE SINDICÂNCIA PARA APURAR O CASO E STEPANENKO 
REVIDOU, EXONERANDO O DIRETOR SÉRGIO ZENDRON, RESPONSÁVEL PELO PROGRAMA NACIONAL DE DESESTATIZAÇÃO. A CRISE EVOLUIU ATÉ A DEMISSÃO DE DELBEN LEITE, EM AGOSTO DE 1993. 1994 - INTEGROU O CONSELHO DE ADMINISTRAÇÃO DAS EMPRESAS ENERGÉTICAS DO ESTADO DE SÃO PAULO (CESP)

1998 - CONDUZIDO À PRESIDÊNCIA DA ABIMAQ E DO SINDIMAQ, PARA UM MANDATO DE TRÊS ANOS, TORNANDO-SE AO MESMO TEMPO DIRETOR-PRESIDENTE DA FORT KNOX SISTEMAS DE SEGURANÇA LTDA. E SÓCIO-DIRETOR DA FK COMÉRCIO DE PRODUTOS DE SEGURANÇA E SERVIÇOS LTDA. NOVAMENTE À PRESIDÊNCIA DA ABIMAQ E DO SINDIMAQ ONDE PERMANECERIA ATÉ MEADOS DE 2009, QUANDO FOI SUBSTITUÍDO POR LUIZ AUBERT NETO E DESLIGOU-SE DA INSTITUIÇÃOPOSSUI TRÊS PATENTES REGISTRADAS EM SEU NOME NO INSTITUTO NACIONAL DE PROPRIEDADE INDUSTRIAL (INPI): LAVADOR DE ROLOS (MU7002240-2); FRAGMENTADOR DE DOCUMENTOS (MU710225-89); E SERRILHADEIRA DE MESA (PI9305377-0).

FILIAÇÃO PARTIDÁRIA: PMDB

PARENTESCO: FILHO DE EDGAR DE SOUSA LEITE E DE NORMA MARIA DELBEN LEITE. DIVORCIADO, TEVE TRÊS FILHOS. 
PRESIDENTE: ITAMAR FRANCO

PERÍODO DA HISTÓRIA: DEMOCRACIA

GESTÃO: SETEMBRO 1993 - JANEIRO 1995

LOCAL E DATA DE NASCIMENTO: 01/03/1952

LOCAL E DATA DE MORTE:

FORMAÇÃO/PROFISSÃO:

1969-1974 - AINDA ESTUDANTE SECUNDARISTA, PARTICIPOU NA CAPITAL PAULISTA, DURANTE O GOVERNO DO GENERAL EMÍLIO MÉDICI DE MOVIMENTOS CLANDESTINOS DE OPOSIÇÃO AO REGIME MILITAR. PRESO E TORTURADO EM 1970, NO ANO SEGUINTE FOI DENUNCIADO PELA JUSTIÇA MILITAR, COM MAIS 34 PESSOAS, POR SUBVERSÃO E PARTICIPAÇÃO NA VANGUARDA ARMADA REVOLUCIONÁRIAPALMARES (VAR-PALMARES).

1975 - FORMOU-SE EM ECONOMIA PELA UNIVERSIDADE DE SÃO PAULO (USP).

1992 - DOUTOUROU-SE NO MASSACHUSETTS INSTITUTE OF TECHNOLOGY (MIT), NOS ESTADOS UNIDOS.

\section{CARREIRA:}

1978 -1979 PROFESSOR CONVIDADO DO INSTITUTE FOR ADVANCED STUDY.

1980 -1984 LECIONOU NA USP E NA PONTIFÍCIA UNIVERSIDADE CATÓLICA DO RIO DE JANEIRO (PUCRIO)

1984-1985 PROFESSOR VISITANTE DA SMITHSONIAN INSTITUTION (EUA)

1985 - SECRETÁRIO DA COORDENAÇÃO ECONÔMICA E SOCIAL.

1986 - DIRETOR DA ÁREA BANCÁRIA DO BANCO CENTRAL DO BRASIL ( PLANO CRUZADO)

1987-- DIRETOR DA BRASIL WARRANT

1988 - VICE-PRESIDENTE DO UNIBANCO - ENTÃO O QUARTO MAIOR BANCO PRIVADO DO PAÍS.

1993 - PRESIDENTE BNDES (UM DOS PRINCIPAIS IDEALIZADORES DO PLANO REAL)

1995 - PRESIDENTE DO BANCO CENTRAL

1996 - SÓCIO-DIRETOR DA OPPORTUNITY ASSET MANAGEMENT LTDA RJ ( APÓS A VENDA DA VALE DO RIO DOCE - VENCEDORA DO LEILÃO DA TELEBRÁS E SUSPEITA DE INFORMAÇÕES PRIVILEGIADAS) 
2008 - SÓCIO DO COMITÊ EXECUTIVO DA BTG - BANKING AND TRADING GROUP

MEMBRO DO CONSELHO DE ADMINISTRAÇÃO DO BANCO ITAÚ HOLDING FINANCEIRA S.A, DO CONSELHO CURADOR DA FUNDAÇÃO PADRE ANCHIETA E DO CONSELHO CONSULTIVO DO INSTITUTO MOREIRA SALLES.

FILIAÇÃO PARTIDÁRIA: PSDB

PARENTESCO: FILHO DE RIAD ARIDA E DE ALICE FARAH ARIDA. TEVE DUAS FILHAS DO PRIMEIRO CASAMENTO. CASOU-SE, MAIS TARDE, COM ELENA LANDAU, EX-DIRETORA DE DESESTATIZAÇÃO DO BNDES. 
PRESIDENTE: FERNANDO HENRIQUE CARDOSO

PERÍODO DA HISTÓRIA: DEMOCRACIA

GESTÃO: JANEIRO 1995 - NOVEMBRO 1995

LOCAL E DATA DE NASCIMENTO: $14 / 02 / 1942$ - LAMBARI/MG

LOCAL E DATA DE MORTE:

FORMAÇÃO/PROFISSÃO:

1948-1961FEZ OS ESTUDOS PRIMÁRIOS EM SUA CIDADE NATAL. NO ANO SEGUINTE, A FAMÍLIA TRANSFERIU-SE PARA BELO HORIZONTE

1959 - COMPLETOU O CURSO SECUNDÁRIO EM AO INGRESSAR NA

1960-1963 - FACULDADE DE CIÊNCIAS ECONÔMICAS DA UNIVERSIDADE FEDERAL DE MINAS GERAIS (UFMG), TOMOU CONTATO COM O PENSAMENTO DA COMISSÃO ECONÔMICA PARA A AMÉRICA LATINA (CEPAL), ORGANISMO DA ORGANIZAÇÃO DAS NAÇÕES UNIDAS (ONU), DE CUJOS MEMBROS, ESPECIALMENTE RAÚL PREBISCH, CELSO FURTADO E INÁCIO RANGEL, SOFREU INFLUÊNCIA MARCANTE 1960-1963 FOI REDATOR DE ANAIS E DOCUMENTOS PARLAMENTARES DA ASSEMBLEIA LEGISLATIVA DE MINAS GERAIS.

1964 - CURSO DE APERFEIÇOAMENTO DE ECONOMISTAS DA FUNDAÇÃO GETULIO VARGAS (FGV). AINDA NESSE ANO, INICIOU O CURSO DE PÓS-GRADUAÇÃO NA UNIVERSIDADE DE YALE, EM NEW HAVEN (EUA). ALI ABSORVEU O PENSAMENTO NEOKEYNESIANO APRESENTADO PELOS PROFESSORES MÁRIO HENRIQUE SIMONSEN, JAMES TOBIN E CARLOS F. DÍAZ-ALEJANDRO.

1965 - OBTEVE O TÍTULO DE MASTER OF ARTSE TRABALHOU, DE JUNHO A JULHO, COMO PESQUISADORASSISTENTE NA ORGANIZAÇÃO INTERNACIONAL DO CAFÉ, EM LONDRES. PROSSEGUINDO EM SUA FORMAÇÃO UNIVERSITÁRIA, DOUTOROU-SE EM 1968.

1970-1971 LECIONA NA ESCOLA DE PÓS-GRADUAÇÃO EM ECONOMIA DA FUNDAÇÃO GETULIO VARGAS.

1973 A 1975 LECIONA NA UNIVERSIDADE DE BRASÍLIA ONDE TRABALHOU DE NESTE ÚLTIMO ANO, NO MÊS DE AGOSTO, RETORNOU AOS ESTADOS UNIDOS GRAÇAS A UMA BOLSA DE PÓS-DOUTORAMENTO OFERECIDA PELO CONSELHO NACIONAL DE PESQUISAS CNPQ, NO MASSACHUSETTS INSTITUTE OF TECHNOLOGY (MIT), EM CAMBRIDGE, LÁ PERMANECENDO ATÉ JULHO DE 1977.

1979 - TORNOU-SE CONSULTOR DO GRUPO DOS 24 PARA ASSUNTOS MONETÁRIOS INTERNACIONAIS, EM WASHINGTON, FUNÇÃO QUE EXERCERIA ATÉ 1992.

1981 -INGRESSOU NO CORPO DOCENTE DA PONTIFÍCIA UNIVERSIDADE CATÓLICA (PUC) DO RIO DE JANEIRO . ENTRE JANEIRO E JULHO DE 1984, AUSENTOU-SE MAIS UMA VEZ DO PAÍS, POR CONTA DE UMA SEGUNDA BOLSA PÓS-DOUTORAMENTO DO CNPQ, DA COMISSÃO NACIONAL PARA A REFORMULAÇÃO DA EDUCAÇÃO SUPERIOR BRASILEIRA, EM BRASÍLIA. DURANTE O GOVERNO DO 
PRESIDENTE ERNESTO GEISEL (1979-1985), PUBLICOU VÁRIAS OBRAS CRITICANDO AS MEDIDAS TOMADAS EM RELAÇÃO À DISTRIBUIÇÃO DE RENDA E A CRESCENTE DESNACIONALIZAÇÃO DA INDÚSTRIA BRASILEIRA.

CARREIRA:

1985-1990 -INTEGROU A EQUIPE QUE FORMULOU O PLANO DE ESTABILIZAÇÃO ECONÔMICA, BATIZADO DE PLANO CRUZADO.

1986 - PRESIDENTE DO INSTITUTO BRASILEIRO DE GEOGRAFIA E ESTATÍSTICA (IBGE)

1987-1993 CO-DIRETOR, COM SEBASTIAN EDWARDS, DO SEMINÁRIO INTERAMERICANO EM ECONOMIA, CONFERÊNCIA ANUAL PATROCINADA CONJUNTAMENTE PELO NATIONAL BUREAU OF ECONOMIC RESEARCH E A PUC/RJ

1987-1992 - CONSULTOR DA CÂMARA DE COMÉRCIO AMERICANA DO RIO DE JANEIRO (1987-1992); MEMBRO DO GRUPO CONSULTOR PARA TEMAS ECONÔMICOS INTERNACIONAIS DO WORLD INSTITUTE FOR DEVELOPMENT ECONOMICS RESEARCH (WIDER) DA ONU, EM HELSINQUE

1987-1994 - MEMBRO DO COMITÊ PARA O PLANEJAMENTO DO DESENVOLVIMENTO DO CONSELHO ECONÔMICO E SOCIAL DAS NAÇÕES UNIDAS, EM NOVA IORQUE

1989 TORNOU-SE NO MESMO ANO MEMBRO DO DIRETÓRIO NACIONAL E, EM 1992, DO DIRETÓRIO REGIONAL FLUMINENSE.

1992-1995 - MINISTRO DA FAZENDA DO PRESIDENTE ITAMAR FRANCO (FORMULOU O PLANO REAL - O PLANO INTRODUZIU A UNIDADE REFERENCIAL DE VALOR (URV) E, EM $1^{\circ}$ DE JULHO, A NOVA MOEDA BRASILEIRA - O REAL).

1993 - 1995 - PRESIDENTE DO BANCO NACIONAL DO DESENVOLVIMENTO ECONÔMICO E SOCIAL (BNDES). ATUOU COMO ASSESSOR ESPECIAL PARA A ÁREA MONETÁRIA DE FERNANDO HENRIQUE CARDOSO. PROFESSOR-TITULAR DE ECONOMIA DA UNIVERSIDADE FEDERAL DO RIO DE JANEIRO (UFRJ) 1996 - CONSELHEIRO SÊNIOR DO BBA CREDITANSTALT, PRIMEIRO EM SÃO PAULO E, A PARTIR DE OUTUBRO DE 1998, EM NOVA IORQUE. AINDA EM 1996, DEIXOU DE INTEGRAR O DIRETÓRIO NACIONAL DO PSDB. EM JANEIRO DE 1997, FOI UM DOS SÓCIOS FUNDADORES DO VIVACRED, AGÊNCIA DE MICROCRÉDITO ASSOCIADA AO VIVA RIO.

2003 - EDMAR BACHA TORNOU-SE CONSELHEIRO ECONÔMICO DO GOVERNADOR AÉCIO NEVES E PASSOU A INTEGRAR O CONSELHO DE ADMINISTRAÇÃO DO BANCO ITAÚ-BBA (ANTIGO BANCO BBACREDITANSTALT) E CONTINUOU ATUANDO COMO CONSULTOR SÊNIOR DA INSTITUIÇÃO. TORNOU-SE PROFESSOR-CONFERENCISTA DO CURSO DE MESTRADO EM RELAÇÕES INTERNACIONAIS DO INSTITUTO RIO BRANCO, DO MINISTÉRIO DAS RELAÇÕES EXTERIORES, EM BRASÍLIA

2004 - FUNDADOR, E DIRETOR, DO INSTITUTO DE ESTUDOS DE POLÍTICA ECONÔMICA/CASA DAS GARÇAS (IEPE/CDG)RJ CONSIDERADO UMA SUCURSAL DO DEPARTAMENTO DE ECONOMIA DA PUC, POR CONTAR COM UM GRANDE NÚMERO DE EX-ALUNOS E PROFESSORES DAQUELA UNIVERSIDADE, O IEPE/CDG TINHA TAMBÉM COMO MARCA DE ORIGEM UMA ESTREITA RELAÇÃO COM O PSDB. 
FILIAÇÃO PARTIDÁRIA: PMDB - PSDB

PARENTESCO: FILHO DE FELÍCIO BACHA, COMERCIANTE, E DE MARIA DE JESUS LISBOA BACHA, PROFESSORA PRIMÁRIA. VÁRIOS PARENTES SEUS OCUPARAM CARGOS PÚBLICOS, ENTRE OS QUAIS JOÃO LISBOA, SEU AVÔ MATERNO, QUE FOI DEPUTADO ESTADUAL E FEDERAL POR MINAS GERAIS NAS DÉCADAS DE 1930 E 1940, E VALDIR LISBOA, SEU TIO MATERNO, QUE EXERCEU MANDATOS NA ASSEMBLEIA LEGISLATIVA MINEIRA NO PERÍODO 1946-1954. FOI CASADO COM ELIANA A. CARDOSO. DIVORCIADO, CASOU-SE COM ANDREIA GOUVEIA DE LIMA, COM QUEM TEVE DOIS FILHOS. SEPARADO, CASOU-SE PELA TERCEIRA VEZ COM MARIA LAURA VIVEIROS DE CASTRO CAVALCANTI. 
24 - DIRETOR: LUIZ CARLOS MENDONÇA DE BARROS

PRESIDENTE: FERNANDO HENRIQUE CARDOSO

PERÍODO DA HISTÓRIA: DEMOCRACIA

GESTÃO: NOVEMBRO Q995 - ABRIL 1998

LOCAL E DATA DE NASCIMENTO: 28/11/1942 - SÃO PAULO

LOCAL E DATA DE MORTE:

FORMAÇÃO/PROFISSÃO:

FEZ OS ESTUDOS SECUNDÁRIOS NO COLÉGIO SANTA CRUZ E PRESIDIU NA ÉPOCA A UNIÃO ESTADUAL DOS ESTUDANTES (UEE) DE SÃO PAULO.

1964 - CURSOU ENGENHARIA DE PRODUÇÃO NA ESCOLA POLITÉCNICA DA UNIVERSIDADE DE SÃO PAULO (USP) E DURANTE O CURSO SUPERIOR FOI LIGADO À AÇÃO POPULAR (AP), ORGANIZAÇÃO CLANDESTINA DE ESQUERDA QUE FAZIA OPOSIÇÃO AO REGIME MILITAR IMPLANTADO EM ABRIL DE 1964.

1967 - PÓS-GRADUAÇÃO EM POLÍTICA DE NEGÓCIOS DA PEQUENA E MÉDIA EMPRESA NA FACULDADE DE CIÊNCIAS ECONÔMICAS E ADMINISTRATIVAS DA USP.

CARREIRA: 1967 - ANALISTA FINANCEIRO NO BANCO DE INVESTIMENTO INDUSTRIAL (INVESTBANCO) 1968 - LECIONOU ESTATÍSTICA E MÉTODOS QUANTITATIVOS NA ESCOLA DE ADMINISTRAÇÃO DE EMPRESAS (SP-FGV). E SE PROFESSOR DE FINANÇAS E DE ESTATÍSTICA NA FACULDADE DE ADMINISTRAÇÃO E ECONOMIA DE PIRACICABA (SP), NA QUAL PERMANECERIA ATÉ 1971.

1970 - IMPLANTOU O DEPARTAMENTO DE OPEN MARKETNO INVESTBANCO E TORNOU-SE GERENTE E SUPERINTENDENTE DE OPERAÇÕES NAS ÁREAS DE FINANCIAMENTO E CAPTAÇÃO, ALÉM DE REPRESENTANTE DO BANCO NA ASSOCIAÇÃO NACIONAL DA INDÚSTRIA DE MÁQUINAS E AUTOPEÇAS (ANDIMA) - MEMBRO DO CONSELHO FISCAL DA MERCANTIL PARTICIPAÇÕES ADMINISTRATIVAS (MEPASA), DIRETOR-PRESIDENTE DA INVESTLEASING, EMPRESA DE LOCAÇÃO DE MÁQUINAS E EQUIPAMENTOS, E DA COMPANHIA AGROPECUÁRIA BANDEIRANTES. COM MAIS TRÊS SÓCIOS

1972 - FUNDOU A CORRETORA DE CÂMBIO E VALORES IMOBILIÁRIOS PATENTE, QUE ATUAVA NA BOLSA DE VALORES DE SÃO PAULO

1973 - CONSULTOR DA HIDROBRASILEIRA, FIRMA DE ENGENHARIA E CONSULTORIA TÉCNICA.

1974 - ASSOCIOU-SE AO IRMÃO JOSÉ ROBERTO E A IBRAHIM ERIS, E FUNDOU A CONSULTORA MBE ASSOCIADOS.

1980 - PASSOU A INTEGRAR O COMITÊ TÉCNICO DA ANDIMA.

1981 - TORNOU-SE ARTICULISTA DO JORNAL FOLHA DE S. PAULOE PASSOU A ESCREVER UMA COLUNA SEMANAL ATÉ 1991.

1983 - DIRETOR DO BANCO DE INVESTIMENTOS PLANIBANC, ASSOCIADO A QUATRO COMPANHIAS VOTORANTIM, PÃO DE AÇÚCAR, BRASMOTOR E BARDE. CONSULTOR DO GRUPO DE CONJUNTURA ECONÔMICA DO CENTRO BRASILEIRO DE ANÁLISE E PLANEJAMENTO (CEBRAP).

1985 - DIRETOR DE MERCADO DE CAPITAIS DO BANCO CENTRAL, EM BRASÍLIA E MEMBRO DO CONSELHO MONETÁRIO NACIONAL, ONDE PERMANECERIA ATÉ MARÇO DE

1987 - PROFESSOR DO CURSO DE DOUTORADO DO INSTITUTO DE ECONOMIA DA UNICAMP. 
1993 - FUNDOU, COM O ECONOMISTA ANDRÉ LARA RESENDE E MAIS TRÊS SÓCIOS, O BANCO MATRIX, NO QUAL SE TORNOU DIRETOR E RESPONSÁVEL PELA TESOURARIA INTERNACIONAL E PELO SETOR DE ESTUDOS ECONÔMICOS. ATUANDO BASICAMENTE NOS MERCADOS DE RENDA FIXA E CÂMBIO, E NA ADMINISTRAÇÃO DE RECURSOS DE TERCEIROS, INCLUSIVE DO EXTERIOR, PARA APLICAÇÃO NO BRASIL, EM DOIS ANOS O MATRIX SE TORNOU O BANCO DE MAIOR RENTABILIDADE DO PAÍS.

2000 - APÓS UMA SÉRIE DE ACUSAÇÕES E ESCANDALOS QUE O ENVOLVIA CRIOU O SITE PRIMEIRA LEITURA EM SOCIEDADE COM O JORNALISTA REINALDO AZEVEDO, E EM 2001, A EDITORA DO MESMO NOME, QUE PUBLICOU UMA REVISTA MENSAL ATÉ 2006. AINDA EM 2001, FUNDOU A MBG \& ASSOCIADOS PARA OFERECER CURSOS PROFISSIONALIZANTES À DISTÂNCIA, EM PARCERIA COM SEU IRMÃO JOSÉ ROBERTO MENDONÇA DE BARROS E LÍDIA GOLDEINSTEIN. EM ABRIL DO MESMO ANO FUNDOU COM OUTROS SÓCIOS A QUEST INVESTIMENTOS, GESTORA INDEPENDENTE DE RECURSOS

FINANCEIROS, TORNANDO-SE RESPONSÁVEL PELA ESTRATÉGIA MACROECONÔMICA DOS FUNDOS DA EMPRESA. EM 2003 VOLTOU A ESCREVER PARA O JORNAL FOLHA DE S. PAULOE NO ANO SEGUINTE DEIXOU A EDITORA PRIMEIRA LEITURA. AINDA LIGADO AO PSDB, EM 2006 AUXILIOU AS CAMPANHAS DE GERALDO ALCKMIN, PARA PRESIDÊNCIA DA REPÚBLICA, E DE JOSÉ SERRA, PARA O GOVERNO DE SÃO PAULO.

FILIAÇÃO PARTIDÁRIA: PSDB

PARENTESCO: FILHO DE LEOVIGILDO MENDONÇA DE BARROS E DE NÍSIA MAURÍCIO MENDONÇA DE BARROS. SEU IRMÃO, JOSÉ ROBERTO MENDONÇA DE BARROS, FOI SECRETÁRIO DE POLÍTICA ECONÔMICA DO MINISTÉRIO DA FAZENDA ENTRE 1995 E 1998, NO PRIMEIRO GOVERNO DE FERNANDO HENRIQUE CARDOSO. CASOU-SE COM VITÓRIA MARIA CARDOSO MENDONÇA DE BARROS, COM QUEM TEVE TRÊS FILHOS. 
PRESIDENTE: FERNANDO HENRIQUE CARDOSO

PERÍODO DA HISTÓRIA: DEMOCRACIA

GESTÃO: ABRIL 1998 - NOVEMBRO 1998

LOCAL E DATA DE NASCIMENTO:

LOCAL E DATA DE MORTE:

FORMAÇÃO/PROFISSÃO:

1973 - FORMADO EM ECONOMIA PELA (PUC-RIO)

1975 - FEZ O MESTRADO EM ECONOMIA NA ESCOLA DE PÓS-GRADUAÇÃO EM ECONOMIA FGV/RJ

1979 -OBTEVE O TÍTULO DE PHD EM ECONOMIA PELOMASSACHUSETTS INSTITUTE OF TECHNOLOGY EUA.

CARREIRA: 1979-1988 - LECIONAOU NO DEPARTAMENTO DE ECONOMIA DA PUC-RIO PARALELAMENTE ÀS SUAS ATIVIDADES DOCENTES

1980- 1985 - SÓCIO E DIRETOR ADMINISTRATIVO DO BANCO DE INVESTIMENTOS GARANTIA. NOS PRIMEIROS ANOS DA DÉCADA DE 1980, JUNTAMENTE COM O SEU COLEGA DE GRADUAÇÃO NA PUC-RIO, PÉRSIO ARIDA, INTERVEIO NA DISCUSSÃO DO PROCESSO DE TRANSIÇÃO DO REGIME MILITAR PARA A DEMOCRACIA, EM UM MOMENTO EM QUE GANHAVA ESPAÇO A PROPOSTA DE PACTO SOCIAL DO GOVERNADOR DE MINAS GERAIS, TANCREDO NEVES, QUE VIRIA A SER O CANDIDATO DA OPOSIÇÃO À PRESIDÊNCIA DA REPÚBLICA, POR ELEIÇÕES INDIRETAS, NA SUECESSÃO DO GENERAL JOÃO BATISTA FIGUEIREDO. PREOCUPADO COM A SUPERAÇÃO DA CRISE ECONÔMICO-FINANCEIRA QUE O PAÍS ATRAVESSAVA, DIVULGOU, EM CONJUNTO COM ARIDA, IDEIAS QUE VIRIAM A CONFIGURAR O EIXO DO ARTIGO "INERTIAL INFLATION AND MONETARY REFORM IN BRAZIL", PUBLICADO PELOS DOIS ECONOMISTAS EM 1985 NA COLETÂNEA ORGANIZADA POR J. WILLIAMSON, INFLATION AND INDEXATION: ARGENTINA, BRAZIL AND ISRAEL (BOSTON, MIT PRESS).

1984-1985 - DIRETOR EXTERNO DA COMPANHIA FERRO BRASILEIRO, CARGO QUE VOLTARIA A OCUPAR ENTRE 1987 E 1990.

1985 E 1986, INTEGRANTE DO CONSELHO DE ADMINISTRAÇÃO DO BANCO CENTRAL - PLANO CRUZADO DO PRESIDENTE JOSÉ SARNEY

1987-1989 - DIRETOR EXTERNO DAS LOJAS AMERICANAS E DIRETOR EXECUTIVO DO BRASIL WARRANT ADMINISTRAÇÃO DE BENS E EMPRESAS, HOLDING DO GRUPO MOREIRA SALLES. MEMBRO DO CONSELHO DIRETOR E VICE-PRESIDENTE EXECUTIVO DA UNIÃO DE BANCOS BRASILEIROS

1989-1993 - UNIBANCO, INTEGRANTE DO GRUPO MOREIRA SALLES

1990-1997 - CONSELHO CONSULTIVO DO THE CAPITAL GROUP, SEDIADA EM LOS ANGELES, ESTADOS UNIDOS

1993 - DE VOLTA AO SETOR PÚBLICO, FOI NEGOCIADOR-CHEFE DA DÍVIDA EXTERNA. SÓCIO-DIRETOR DO BANCO MATRIX JUNTAMENTE COM LUIS CARLOS MENDONÇA DE BARROS E MAIS TRÊS SÓCIOS UM DOS FUNDADORES NO GOVERNO DO PRESIDENTE ITAMAR FRANCO (1992-1994).ATUANDO BASICAMENTE NOS MERCADOS DE RENDA FIXA E CÂMBIO, E NA ADMINISTRAÇÃO DE RECURSOS DE TERCEIROS, INCLUSIVE DO EXTERIOR, PARA APLICAÇÃO NO BRASIL, O MATRIX VIRIA A SER, EM 1995, O BANCO DE MAIOR RENTABILIDADE DO PAÍS. EM MARÇO DESSE ANO, O MATRIX SERIA ACUSADO DE TER OBTIDO INFORMAÇÕES PRIVILEGIADAS SOBRE MUDANÇAS NA POLÍTICA CAMBIAL. 
1995 - COM A POSSE DE FERNANDO HENRIQUE CARDOSO (PDSB), ASSUME O CARGO DE ASSESSOR ESPECIAL DA PRESIDÊNCIA. FOI UM DOS INTEGRANTES DA EQUIPE ECONÔMICA QUE IMPLEMENTOU O PLANO REAL . 1998 - PRESIDENTE DO BNDES

2000-2006 - MEMBRO DO CONSELHO CONSULTIVO DAS FACULDADES IBMEC CONSULTOR DE INVESTIMENTOS

2001-2007 - MEMBRO DO CONSELHO DOS FUNDOS DE INVESTIMENTOS DA CLARITA INVESTIMENTS INCE 2002-2003 - MEMBRO DO CONSELHO DE ADMINSITRAÇÃO DA GERDAU S. A. E DA METALÚRGICA GERDAU S. A. NESSE PERÍODO, FOI TAMBÉM PESQUISADOR VISITANTE DA ST. ANTONY'S COLLEGE, DA UNIVERSIDADE DE OXFORD, NA INGLATERRA

2006 - RECEBEU O PRÊMIO DE "ECONOMISTA DO ANO" PELA ORDEM DOS ECONOMISTAS DO BRASIL. 2008 -MEMBRO DO CONSELHO CONSULTIVO DA FUNDAÇÃO ISRAEL PINHEIRO (FIP), MAIS RECENTEMENTE TORNOU-SE SÓCIO-DIRETOR DA LANX CAPITAL INVESTIMENTOS, MEMBRO DO CONSELHO DE ADMINISTRAÇÃO DA RB CAPITAL, E MEMBRO ASSOCIADO DO INSTITUTO DE ESTUDOS DE POLÍTICA ECONÔMICA - CASA DAS GARÇAS, INSTITUIÇÃO CRIADA EM 2003 E QUE REÚNE ECONOMISTAS E PESQUISADORES LIGADOS AO PSDB.

2009 - MEMBRO DO CONSELHO CONSULTIVO INTERNACIONAL DO ITAÚ UNIBANCO, PRESIDIDO POR PEDRO MALAN, EX-MINISTRO DA FAZENDA DOS DOIS GOVERNOS DE FERNANDO HENRIQUE CARDOSO (1995-2002).

FILIAÇÃO PARTIDÁRIA: PSDB

PARENTESCO: FILHO DO JORNALISTA E ESCRITOR OTO LARA RESENDE E DE HELENA PINHEIRO GUIMARÃES. SEU AVÔ MATERNO, ISRAEL PINHEIRO, FOI REVOLUCIONÁRIO DE 1930, CONSTITUINTE DE 1946, DEPUTADO FEDERAL POR MINAS GERAIS ENTRE 1946 E 1956, PREFEITO DO DISTRITO FEDERAL DE 1960 A 1961, E GOVERNADOR DE MINAS GERAIS DE 1966-1971. SEU TIO MATERNO, ISRAEL PINHEIRO FILHO, FOI DEPUTADO FEDERAL POR MINAS GERAIS ENTRE 1967 E 1971. CASOU-SE COM A FOTÓGRAFA CLÁUDIA JAGUARIBE, FILHA DO SOCIÓLOGO HÉLIO JAGUARIBE. 


\section{6 - DIRETOR: JOSÉ PIO BORGES DE CASTRO FILHO}

PRESIDENTE: FERNANDO HENRIQUE CARDOSO

PERÍODO DA HISTÓRIA: DEMOCRACIA

GESTÃO: NOVEMBRO DE 1998 - JULHO 1999

LOCAL E DATA DE NASCIMENTO: 31/01/1948 - RIO DE JANEIRO

LOCAL E DATA DE MORTE:

FORMAÇÃO/PROFISSÃO:

1970 - ENGENHARO MECÂNICO PUC-RIO

1971 - MESTRADO EM ENGENHARIA INDUSTRIAL, COM ESPECIALIZAÇÃO EM FINANÇAS, TAMBÉM NA PUCRIO.

1979-1982 - CURSOU A NEW SCHOOL FOR SOCIAL RESEARCH, EM NOVA IORQUE, ONDE OBTEVE O TÍTULO DE MASTER OF ARTS AND PHD CANDIDATE - ECONOMICS

\section{CARREIRA:}

1971 - FOI ADMITIDO COMO ENGENHEIRO NO BANCO NACIONAL DE DESENVOLVIMENTO ECONÔMICO (BNDE).

1974-1975 LICENCIOU-SE DO BNDE E EXERCEU AS FUNÇÕES DE AUDITOR INTERNO E ANALISTA FINANCEIRO DA IBM DO BRASIL LTDA.

1976-1977 - DE VOLTA AO BANCO COMO ASSESSOR DA DIREÇÃO

1977-1979 -GERENTE DO DEPARTAMENTO DE INDÚSTRIAS QUÍMICAS

1977-1979 - SUPERINTENDENTE DA SUBSIDIÁRIA BNDE PARTICIPAÇÕES DE 1977 A 1979. NO PERÍODO COMPREENDIDO ENTRE 1982-1985 -RETORNAR, CHEFIOU O DEPARTAMENTO DE INDÚSTRIAS QUÍMICAS

1985-1990 -PARTICIPOU DOS CONSELHOS DE ADMINISTRAÇÃO DA RIOCELL S.A. E DA CIA. GUATAPARÁ DE PAPEL E CELULOSE (ATUAL VCP). NOVAMENTE AFASTADO DO BNDES, QUE JÁ INCORPORARA O 'S' DE 'SOCIAL', OCUPOU CARGOS DE DESTAQUE NO SETOR PRIVADO: FOI PRESIDENTE DA PRONOR PETROQUÍMICA S.A., DIRETOR DO BBM-BANCO DA BAHIA INVESTIMENTOS S.A., ALÉM DE MEMBRO DOS CONSELHOS DE ADMINISTRAÇÃO DA ENGEPACK EMBALAGENS S.A. E DA YOKOGAWA LATINAMERICA S.A.

1990 - ASSUMIU A VICE-PRESIDÊNCIA DO BNDES, NA GESTÃO DE EDUARDO MODIANO, NO GOVERNO FERNANDO COLLOR DE MELO (1990-1992). NA ÉPOCA, REPRESENTOU O BANCO NA COMISSÃO DIRETORA DO PROGRAMA NACIONAL DE DESESTATIZAÇÃO E PARTICIPOU DOS CONSELHOS DE ADMINISTRAÇÃO DO BNB - BANCO DO NORDESTE DO BRASIL S.A. E DA CENTRAIS ELÉTRICAS BRASILEIRAS S.A. (ELETROBRÁS). PELO PROGRAMA NACIONAL DE PRIVATIZAÇÃO (PND), PRESIDIU A CÂMARA DE LIQUIDAÇÃO E CUSTÓDIA S.A. E FOI VICE-PRESIDENTE DO CONSELHO DA COMPANHIA PETROQUÍMICA DO SUL (COPESUL), DA USINAS SIDERÚRGICAS DE MINAS GERAIS S.A. (USIMINAS) E DA REDE FERROVIÁRIA FEDERAL S.A. TODAS ESSAS EMPRESAS FORAM PRIVATIZADAS DE ACORDO COM OS OBJETIVOS E CRONOGRAMAS DO PND. ENTRE 1992 E 1995, DE VOLTA AO SETOR PRIVADO, FOI PRESIDENTE DA COMPANHIA DE SEGUROS DA BAHIA, DIRETOR DA PETROQUÍMICA DA BAHIA S.A, MEMBRO DOS CONSELHOS DE ADMINISTRAÇÃO DA NITROCARBONO S.A., DA POLICARBONATOS DO BRASIL S.A., DA ENGEPACK EMBALAGENS S.A., E PRESIDENTE DA YOKOGAWA LATINAMÉRICA S.A.

1995 - NO GOVERNO FERNANDO HENRIQUE CARDOSO (1995-2003) VICE-PRESIDENTE NA GESTÃO DE LUÍS CARLOS MENDONÇA DE BARROS, E GESTÃO DE ANDRÉ LARA RESENDE, DURANTE A QUAL, NO MÊS| 
DE JULHO, SE CONCRETIZOU, ATRAVÉS DE LEILÃO, A PRIVATIZAÇÃO DO SISTEMA TELEBRÁS. DURANTE ESSE PERÍODO, PARTICIPOU DOS CONSELHOS DE ADMINISTRAÇÃO DA PETRÓLEO BRASILEIRO S.A. (PETROBRAS), DO INSTITUTO NACIONAL DE ALTOS ESTUDOS (INAE), DO GRUPO CONSULTIVO DA CONCORRÊNCIA DO MINISTÉRIO DA JUSTIÇA, E DO COMITÊ EMPRESARIAL PERMANENTE DO MINISTÉRIO DAS RELAÇÕES EXTERIORES. PARTICIPOU TAMBÉM DOS CONSELHOS DE ADMINISTRAÇÃO DA ARACRUZ CELULOSE S.A. E DA TELECOMUNICAÇÕES DO RIO DE JANEIRO S.A. (TELEMAR), APÓS SUA PRIVATIZAÇÃO.

1998 - PRESIDENTE DO BNDES

1999-2002 - DIRETOR DO BANCO LIBERAL S.A.

1999-2001 - DIRETOR DO BANK OF AMÉRICA,

PARTICIPOU DO CONSELHO DE ADMINISTRAÇÃO DA COMPANHIA VALE DO RIO DOCE (VALEPAR S.A.) E DOS CONSELHOS CONSULTIVOS DO CENTRO BRASILEIRO DE RELAÇÕES INTERNACIONAIS (CEBRI), DA FINANCIADORA DE ESTUDOS E PROJETOS (FINEP), VINCULADA AO MINISTÉRIO DA CIÊNCIA E TECNOLOGIA, E DO INSTITUTO LIGHT PARA O DESENVOLVIMENTO URBANO E SOCIAL. NO PERÍODO SEGUINTE, FOI DIRETOR DA VIOLY, BYORUM \& CO., E PARTICIPOU DOS CONSELHOS CONSULTIVOS DO BANCO CALYON (CRÉDIT AGRICOLE - CRÉDIT LYONNAIS) E DO BANCO PRIVADO PORTUGUÊS. TORNOUSE SÓCIO GERENTE DA RJX INVESTIMENTO LTDA., VICE-PRESIDENTE EXECUTIVO DO CEBRI E MEMBRO DO CONSELHO DE ADMINISTRAÇÃO DA RB CAPITAL.

FILIAÇÃO PARTIDÁRIA:

PARENTESCO: FILHO DE JOSÉ PIO BORGES DE CASTRO, CONHECIDO PROFESSOR DE GEOMETRIA ANALÍTICA, E DE CIRCE DE CARVALHO PIO BORGES. 
PRESIDENTE: FERNANDO HENRIQUE CARDOSO

PERÍODO DA HISTÓRIA: DEMOCRACIA

GESTÃO: JULHO 199 - FEVEREIRO 2000

LOCAL E DATA DE NASCIMENTO: $18 / 09 / 1945$ - SÃO PAULO

LOCAL E DATA DE MORTE:

FORMAÇÃO/PROFISSÃO:1970 - GRADUOU-SE EM ECONOMIA NA FACULDADE DE ECONOMIA E ADMINISTRAÇÃO (FEA-USP)

1971-1991- PROFESSOR DESSA UNIVERSIDADE

1972 - CONCLUIU O MESTRADO EM ECONOMIA NO INSTITUTO DE PESQUISAS ECONÔMICAS (IPE) DA USP

1975 - OBTEVE O MASTER OF ARTS NA UNIVERSIDADE DE BERKELEY, CALIFÓRNIA

1976-1991 - PROFESSOR DO IPE-USP E PESQUISADOR DA FUNDAÇÃO DE PESQUISAS ECONÔMICAS (FIPE) DA USP

1982 - NESSE ANO OBTEVE O PHILOSOPHY DOCTOR (PH.D) EM ECONOMIA, TAMBÉM EM BERKELEY. DURANTE SEUS ESTUDOS EM BERKELEY, FOI ALUNO DE ALBERT FISHLOW, QUE HAVIA ESTADO NO BRASIL NOS ANOS 1960 CHEFIANDO UMA EQUIPE DE CONSULTORES NO INSTITUTO DE PESQUISA ECONÔMICA APLICADA (IPEA), ONDE REALIZOU ESTUDOS SOBRE O DESENVOLVIMENTO ECONÔMICO E SOCIAL DE LONGO PRAZO NOS PAÍSES EM DESENVOLVIMENTO.

\section{CARREIRA:}

1983-1985 - PARALELAMENTE À VIDA ACADÊMICA PRESIDIU A DISTRIBUIDORA DE TÍTULOS E VALORES MOBILIÁRIOS DO ESTADO DE SÃO PAULO E FOI ASSESSOR DO GOVERNADOR FRANCO MONTORO (19831987). INTEGRANTE DO GRUPO NOVOS ECONOMISTAS PAULISTAS, FORMADO POR JOSÉ SERRA, LUCIANO COUTINHO, MARCOS FONSECA, ANDRÉ FRANCO MONTORO FILHO, ENTRE OUTROS, COMPARTILHAVA A TESE DE QUE O APERTO MONETÁRIO E O AJUSTE FISCAL NÃO ERAM SUFICIENTES PARA COMBATER A INFLAÇÃO, SENDO NECESSÁRIO BUSCAR O EQUILÍBRIO DAS CONTAS PÚBLICAS. ESSE GRUPO CHEGOU AO PODER COM A IDA DE JOÃO SAYAD PARA SECRETARIA DE PLANEJAMENTO DA PRESIDÊNCIA DA REPÚBLICA (SEPLAN) EM 1985, NO GOVERNO JOSÉ SARNEY (1985-1990).

SECRETÁRIO-GERAL DA SEPLAN E PRESIDENTE DO IPEA.

1986 - FOI PRIMEIRO-SECRETÁRIO SEPLAN COM A TAREFA DE IMPLEMENTAR UM SISTEMA DE EXECUÇÃO FINANCEIRA DO ORÇAMENTO DO GOVERNO FEDERAL.

1987 - PRESTACONSULTORIA PARA EMPRESAS PRIVADAS NA ÁREA DE REESTRUTURAÇÃO E PLANEJAMENTO

- SÓCIO-DIRETOR DA CONSULTORIA E EMPREENDIMENTOS INDUSTRIAIS (CONSEMP) ATÉ 1994.

1995 - SECRETÁRIO-EXECUTIVO DESSE MINISTÉRIO E DE PRESIDENTE DO IPEA

1995-1996 PARTICIPOU DO CONSELHO ADMINISTRATIVO DO BANCO DO BRASIL PERTENCE AO GRUPO DOS "DESENVOLVIMENTISTAS" JUNTO COM ANDRÉ LARA RESENDE (BNDES), E LUÍS CARLOS MENDONÇA DE BARROS, MINISTRO DAS COMUNICAÇÕES

1999 - PRESIDENTE DO BANCO DO BRASIL , POR INDICAÇÃO DE JOSÉ SERRA., ASSUME A PRESIDÊNCIA DO BNDES.

2002 - MEMBRO DO CONSELHO DE ADMINISTRAÇÃO DA CAIXA DE PREVIDÊNCIA DOS FUNCIONÁRIOS DO BANCO DO BRASIL (PREVI)

2003 - ASSUMIU A SECRETARIA DE ECONOMIA E PLANEJAMENTO DO ESTADO DE SÃO PAULO, NA GESTÃO GERALDO ALCKMIN. OCUPOU O CARGO ATÉ JANEIRO DE 2005 
- FOI AINDA MEMBRO DOS CONSELHOS ADMINISTRATIVOS DA CYRELA BRAZIL REALTY, DA FIPE USP, DA FUNDAÇÃO FACULDADE DE MEDICINA (FFM) DA USP, DO FUNDO SOCIAL DE SOLIDARIEDADE DO GOVERNO DO ESTADO DE SÃO PAULO (FUSSESP), DA CAIXA ECONÔMICA FEDERAL, DA TELECOM ITÁLIA E DA COMPANHIA DE SANEAMENTO BÁSICO DO ESTADO DE SÃO PAULO (SABESP) 2009 - TORNOU-SE PROFESSOR DA FUNDAÇÃO GETÚLIO VARGAS.

FILIAÇÃO PARTIDÁRIA:

PARENTESCO: FILHO DE FÁBIO CALABI E DE AMÉLIA DINEPI CALABI. TEVE DUAS FILHAS E CASOU-SE COM MARTA GROSTEIN MÃE DO APRESENTADOR LUCIANO HUCK 
28 - DIRETOR: FRANÇOIS ROBERT ANDRÉ GROS

PRESIDENTE: FERNANDO HENRIQUE CARDOSO

PERÍODO DA HISTÓRIA: DEMOCRACIA

GESTÃO: FEVEREIRO 2000 - JANEIRO 2002

LOCAL E DATA DE NASCIMENTO: 21/04/1942 - RIO DE JANEIRO

LOCAL E DATA DE MORTE: 20/05/2002 - SÃO PAULO

FORMAÇÃO/PROFISSÃO: 1964 - EDUCADO NOS ESTADOS UNIDOS, FORMOU-SE EM ECONOMIA NA UNIVERSIDADE DE PRINCETON E CURSOU SUA PÓS-GRADUAÇÃO NA UNIVERSIDADE DE COLÚMBIA, ONDE APRESENTOU A DISSERTAÇÃO INVESTIMENTOS ESTRANGEIROS NO BRASIL.

\section{CARREIRA:}

1967 - RETORNA AO BRASIL, COMEÇA SUA CARREIRA PROFISSIONAL NO GRUPO FINANCEIRO METROPOLITANA, EM SÃO PAULO.

1972 - VOLTOU AOS ESTADOS UNIDOS PARA TRABALHAR NA ÁREA INTERNACIONAL DA KIDEER, PEABODY AND CO. INC., UMA DAS MAIS INFLUENTES CORRETORAS NA BOLSA DE VALORES DE NOVA IORQUE.

1975 - DIRETOR DO GRUPO MULTIPLIC- RJ

1977 - SUPERINTENDENTE DE EMPRESAS DA COMISSÃO DE VALORES MOBILIÁRIOS (CVM)

SUA ATUAÇÃO NA CVM FOI MARCADA PELAS DURAS CRÍTICAS AO ENTÃO MINISTRO DA FAZENDA, ERNÂNI GALVEIAS, POR TER AUTORIZADO A VENDA DE UM EXPRESSIVO LOTE DE AÇÕES DA VALE DO RIO DOCE, EM MARÇO DE 1980, SEM AVISO PRÉVIO À BOLSA DE VALORES DO RIO DE JANEIRO, ONDE FOI EFETUADA A TRANSAÇÃO. DURANTE A SUA PERMANÊNCIA NA CVM, ESTREITOU LAÇOS COM MÁRIO HENRIQUE SIMONSEN, EX-MINISTRO DO PLANEJAMENTO E ENTÃO VICE-PRESIDENTE DO CONSELHO DE ADMINISTRAÇÃO DA COMPANHIA BOZANO, SIMONSEN, E COM O DIPLOMATA MARCÍLIO MARQUES MOREIRA, PRIMEIRO-SECRETÁRIO DO MINISTÉRIO DAS RELAÇÕES EXTERIORES

1981 - DIRETOR-EXECUTIVO DO UNIBANCO

1985 - DIRETOR DE MERCADO DE CAPITAIS DO BANCO NACIONAL DO DESENVOLVIMENTO ECONÔMICO E SOCIAL (BNDES)

VENDEU AÇÕES DA PETROBRAS QUE ESTAVAM EM PROPRIEDADE DO BANCO

SUPERVISIONOU OS PROCESSOS DE PRIVATIZAÇÃO DAS EMPRESAS NOVA AMÉRICA E MAFERSA

CENTRAL

DÍLSON FUNARO MINISTRO DA FAZENDA O CONVIDA PARA A PRESIDÊNCIA DO BANCO

1987 - PRESIDENTE DA ARACRUZ CELULOS NEGOCIOU AÇÕES DA EMPRESA QUE ESTAVAM SOB O PODER DO BNDES E A CONSEQÜENTE AMPLIAÇÃO DO SETOR PRIVADO NO SEU CONTROLE ACIONÁRIO.

1989 - PRESIDENTE DO BFC BANCO S.A. PELA SEGUNDA VEZ A PRESIDENTE DO BANCO CENTRAL INDICADO POR MARCÍLIO MARQUES MOREIRA, MINISTRO DA ECONOMIA DO GOVERNO DE FERNANDO COLLOR DE MELO DECLAROU QUE MANTERIA AS LINHAS MESTRAS DA NEGOCIAÇÃO DA DÍVIDA EXTERNA INICIADA PELA EQUIPE ECONÔMICA ANTERIOR. ASSEGUROU AINDA A CONTINUIDADE DA POLÍTICA MONETÁRIA DE CONTROLE RÍGIDO DA EXPANSÃO DA MOEDA E DOS GASTOS PÚBLICOS, E A MANUTENÇÃO DOS ALTOS NÍVEIS DAS TAXAS DE JUROS COMO FORMA DE EVITAR O CRESCIMENTO DA INFLAÇÃO. DEFENDEU TAMBÉM A POLÍTICA DE TAXAS DE CÂMBIO FLUTUANTES DETERMINADAS PELO MERCADO.

1992 - UMA COMISSÃO PARLAMENTAR DE INQUÉRITO (CPI) INVESTIGAVA A PARTICIPAÇÃO DE PAULO CÉSAR FARIAS, TESOUREIRO DA CAMPANHA PRESIDENCIAL DE FERNANDO COLLOR DE MELO, NO ESQUEMA DE CORRUPÇÃO E TRÁFICO DE INFLUÊNCIA NO GOVERNO. NA OCASIÃO, GROS DECLAROU ESTAR SENDO PRESSIONADO POR DEPUTADOS DA CPI, QUE O ACUSAVAM DE RETARDAR AS INVESTIGAÇÕES DE CONTAS BANCÁRIAS DOS ENVOLVIDOS, E POR MEMBROS DO GOVERNO, QUE 
COBRAVAM A INVESTIGAÇÃO DA VIDA BANCÁRIA DE ALGUNS EMPRESÁRIOS E PARLAMENTARES, PRINCIPALMENTE DOS PRÓPRIOS INTEGRANTES DA COMISSÃO. NO MÊS SEGUINTE, AMEAÇOU DEIXAR O CARGO, CASO SE CONCRETIZASSE A LIBERAÇÃO DE RECURSOS PARA OBTENÇÃO DE APOIO PARLAMENTAR DESTINADO A BLOQUEAR A ABERTURA DO PROCESSO DE IMPEACHMENT DE COLLOR. EM SETEMBRO - UM DIA APÓS A CÂMARA DOS DEPUTADOS TER APROVADO A ABERTURA DO PROCESSO DE IMPEACHMENT -, GROS ENTREGOU SUA CARTA DE DEMISSÃO AO MINISTRO MARCÍLIO MARQUES MOREIRA. PORÉM, AO ASSUMIR A PRESIDÊNCIA DA REPÚBLICA EM SUBSTITUIÇÃO A COLLOR, ITAMAR FRANCO CONFIRMOU A PERMANÊNCIA DE FRANCISCO GROS NO CARGO, NO DIA 2 DE OUTUBRO, ATÉ QUE O GOVERNO NOMEASSE A NOVA EQUIPE ECONÔMICA. NO MESMO MÊS, VOLTOU A APRESENTAR SEU PEDIDO DE DEMISSÃO A ITAMAR POR DISCORDAR DOS RUMOS DA POLÍTICA ECONÔMICA APONTADOS PELO GOVERNO, ESPECIALMENTE A INSISTÊNCIA DO PRESIDENTE EM ATACAR A POLÍTICA MONETÁRIA DO BANCO CENTRAL, MARCADA PELA PREDOMINÂNCIA DE TAXAS DE JUROS REAIS E POSITIVAS. AINDA NO CARGO, ENVIOU AO MINISTRO DA AGRICULTURA E DA REFORMA AGRÁRIA, LÁZARO BARBOSA, UMA CARTA DENUNCIANDO IRREGULARIDADES ENCONTRADAS PELO BANCO CENTRAL NA LIBERAÇÃO DE INDENIZAÇÕES POR PERDA DE SAFRA, DETERMINADAS PELA COMISSÃO ESPECIAL DE RECURSOS (CER) DO PROGRAMA DE GARANTIA DE ATIVIDADES AGROPECUÁRIAS (PROAGRO). FINALMENTE, EM NOVEMBRO, DEIXOU A PRESIDÊNCIA DO BANCO CENTRAL, SENDO SUBSTITUÍDO POR GUSTAVO LOIOLA.

1993 - DIRETOR-EXECUTIVO DO BANCO NORTE-AMERICANO MORGAN STANLEY \& CO. INC., EM NOVA IORQUE, FICANDO RESPONSÁVEL PELA ÁREA DA AMÉRICA LATINA. EM DEZEMBRO DE 1995, O BANCO CENTRAL LIQUIDOU EXTRAJUDICIALMENTE O BFC, DO QUAL GROS FORA SÓCIO E PRESIDENTE. EM OUTUBRO DE 1996, A JUSTIÇA DO RIO DE JANEIRO ACOLHEU PEDIDO DO BANCO CENTRAL, ENCAMINHADO PELO MINISTÉRIO PÚBLICO, E DETERMINOU O ARRESTO DOS BENS DOS SÓCIOS E ADMINISTRADORES DO BFC, PARA GARANTIR O PAGAMENTO DE PARTE DOS PREJUÍZOS DOS CREDORES DO BANCO. GROS RETORNOU AO BRASIL EM MAIO DE 1997 POR DECISÃO DO MORGAN STANLEY, POIS A INSTITUIÇÃO ESTAVA INTERESSADA NAS PRIVATIZAÇÕES DE EMPRESAS ESTATAIS.

2000 - PRESIDENTE DO BNDES. DEFENSOR DO PROCESSO DE ABERTURA DA ECONOMIA BRASILEIRA DECORRENTE DA GLOBALIZAÇÃO, BEM COMO DAS PRIVATIZAÇÕES, GROS DEFENDEU QUE A ÁREA SOCIAL DO BANCO NÃO OPERASSE COM RECURSOS A FUNDO PERDIDO, LEVANDO-SE EM CONTA QUE A INSTITUIÇÃO TRABALHAVA COM RECURSOS DO PIS/PASEP E DO FUNDO DE AMPARO AO TRABALHADOR (FAT). DIANTE DAS DENÚNCIAS DE QUE O BNDES ESTARIA FINANCIANDO REFORMAS NAS INSTALAÇÕES DO JOCKEY CLUB BRASILEIRO, NUM MONTANTE DE SETE MILHÕES DE REAIS, RECURSOS REPASSADOS POR UM AGENTE FINANCEIRO DO BANCO, O UNIBANCO. GROS DETERMINOU QUE A ÁREA DE OPERAÇÕES SUSPENDESSE O REPASSE.

2001 - PRESIDENTE DA PETROBRAS FOI UM DOS RESPONSÁVEIS PELA INTRODUÇÃO DAS REGRAS DA GOVERNANÇA CORPORATIVA NA ESTATAL, POIS CONSIDERAVA O TEMA DE GRANDE IMPORTÂNCIA NACIONAL E INTERNACIONAL, AINDA MAIS COM OS ESCÂNDALOS DE MAQUIAGEM DOS RESULTADOS DE GRANDES CORPORAÇÕES NORTE-AMERICANAS COMO A ENRON E A WORLDCOM. PARA GROS, A TRANSPARÊNCIA NA GESTÃO DAS COMPANHIAS E NA RELAÇÃO COM OS INVESTIDORES ERA UM FATOR DECISIVO NA AVALIAÇÃO DAS EMPRESAS PELO MERCADO.

- OS CARGOS DE DIRETOR-PRESIDENTE E MEMBRO DOS CONSELHOS DE ADMINISTRAÇÃO DA FOSFERTIL E DA ULTRAFERTIL EM MAIO DE 2003. TORNOU-SE PRESIDENTE DO CONSELHO DE ADMINISTRAÇÃO DA LOJAS RENNER, MEMBRO DOS CONSELHOS DE ADMINISTRAÇÃO DA GLOBEX UTILIDADES S.A., OCEAN WILSONS LTDA., ENERGIAS DO BRASIL S.A. E AMCHAM - CÂMARA AMERICANA DE COMÉRCIO. TAMBÉM É MEMBRO DOS CONSELHOS CONSULTIVOS DA AIR LIQUIDE DO BRASIL LTDA., SCANIA LATIN AMERICA LTDA., BANCO FINANCIA S.A., BRAZILIAN AMERICAN CHAMBER OF COMMERCE (NEW YORK), THE AMERICAS SOCIETY INC. (NEW YORK) E THE NATURE CONSERVANCY. FOI MEMBRO DO CONSELHO DE ADMINISTRAÇÃO DA OGX, EMPRESA DE PETRÓLEO E GÁS DO GRUPO EBX, DE EIKE BATISTA.

FILIAÇÃO PARTIDÁRIA:

PARENTESCO: FILHO DE ANDRÉ GROS, REPRESENTANTE DA FRANÇA NA CORTE INTERNACIONAL DE HAIA, E DE DULCE SIMÕES CORREIA. FOI CASADO COM SANDRA MATTMAN, COM QUEM TEVE TRÊS FILHOS. 
PRESIDENTE: FERNANDO HENRIQUE CARDOSO

PERÍODO DA HISTÓRIA: DEMOCRACIA

GESTÃO: JANEIRO 2002 - JANEIRO 2003

LOCAL E DATA DE NASCIMENTO: 26/07/1957 - SÃO PAULO

LOCAL E DATA DE MORTE:

FORMAÇÃO/PROFISSÃO:

1979 - GRADUOU-SE EM ECONOMIA PELA UNIVERSIDADE DE NOVA YORQUE

1981 - MESTRE EM RELAÇÕES INTERNACIONAIS PELA UNIVERSIDADE JOHNS HOPKINS, EM BALTIMORE, MARYLAND

1998 - MBA EM CORPORATE FINANCIAL MANAGEMENTPELA HARVARD BUSINESS SCHOOL, EM CAMBRIDGE, MASSACHUSETTS.

\section{CARREIRA:}

1981 - ASSESSOR DO BANCO CITIBANK/CREFISUL DE INVESTIMENTO E,POSTERIORMENTE

1983 - DIRETOR-ADJUNTO DA ÁREA INTERNACIONAL NO MESMO BANCO

1986-1992 - OCUPOU DIVERSOS CARGOS NA ALCOA ALUMÍNIO S.A. PRIMEIRO COMO DIRETOR DA ÁREA

FINANCEIRA E, EM SEGUIDA, COMO VICE-PRESIDENTE DO INSTITUTO CULTURAL DA ALCOA E SUPERINTENDENTE DA ALCOA PREVI, NA QUAL FOIRESPONSÁVEL PELA SEGURADORA E CORRETORA DE SEGUROS

1992 - CHEFIOU A ÁREA DE FINANÇAS COORPORATIVAS DO BANCO DE INVESTIMENTOS GARANTIA, EM SÃO PAULO

1994 -DIRETOR DO BANCO GARANTIA NO RIO DE JANEIRO, DEDICANDO-SE AS ÁREAS COMERCIAIS, DE MERCADOS DE CAPITAIS E DE PRIVATE BANKING

1998 - NO BANCO WARBURG DILLON READ, OCUPOU OS CARGOS DE MANAGING DIRECTOR E DIRETORPRESIDENTE, ALÉM DA LIDERANÇA DA ÁREA DE FINANÇAS CORPORATIVAS.

2000 - A CONVITE DE FRANCISCO GROS INTEGRA A EQUIPE DO BNDES. ASSUME O CARGO DE DIRETOR SUPERINTENDENTE DO BNDES PARTICIPAÇÕES S.A (BNDESPAR), TENDO SIDO RESPONSÁVEL PELO PROCESSO QUE PERMITIU A COMPRA DE AÇÕES DA PETROBRAS COM RECURSOS DO FUNDO DE GARANTIA DO TEMPO DE SERVIÇO (FGTS). EM SEGUIDA, FOI NOMEADO DIRETOR DA SECRETARIA GERAL DE APOIO À DESESTATIZAÇÃO, E RESPONDEU PELAS OPERAÇÕES E SERVIÇOS DE PRIVATIZAÇÃO, ASSIM COMO PELA DIRETORIA DA ÁREA DE PRODUTOS ESTRUTURADOS DO BNDES.

2002 - PRESIDENTE DO BNDES CONCEDENDO UM EMPRÉSTIMO À GLOBO CABO, A ATUAL NET BRASIL. CRIOU AINDA OS PROGRAMAS DE INCENTIVO À ADOÇÃO DE REGRAS DE GOVERNANÇA CORPORATIVA E DE APOIO À EMISSÃO DE TÍTULOS CORPORATIVOS. PERMANECEU À FRENTE DO BNDES ATÉ DEZEMBRO DE 2002

2003 - SÓCIO FUNDADOR DA IPOSEIRA GESTÃO DE ATIVOS

2005 - DESIGNADO CONSELHEIRO DA VARIG E, POSTERIORMENTE, OCUPOU A VICE-PRESIDÊNCIA DO CONSELHO DE ADMINISTRAÇÃO DESSA EMPRESA

2006 -PRESIDENTE DA BHP-BILLITON DO BRASIL.COM A COMPRA DE PARTE DO CAPITAL DA IPOSEIRA PELO UNIBANCO, CHEFIOU A ESTRUTURAÇÃO DO UNIBANCO BANCO DE INVESTIMENTO, RESULTADO DA FUSÃO DA IPOSEIRA COM O GRUPO UNIBANCO.

2009 - INTEGROU O COMITÊ ESPECIAL INDEPENDENTE DO CONSELHO DE ADMINISTRAÇÃO DA ARACRUZ, FOI AINDA, MEMBRO DOS CONSELHOS ADMINISTRATIVOS E CONSULTIVOS DO ABN AMRO BANCO BRASIL, DA TELEMAR, DA VALE DO RIO DOCE, DA ELETROBRÁS E DA SÃO PAULO ALPARGATAS. 
FILIAÇÃO PARTIDÁRIA:

PARENTESCO: FILHO DO MAESTRO ELEAZAR DE CARVALHO E DA COMPOSITORA, PIANISTA E ESCRITORA JOCY DE OLIVEIRA. FOI CASADO COM JULIA MICHAELS, COM QUEM TEVE TRÊS FILHOS. CONTRAIU SEGUNDAS NÚPCIAS COM SONIA QUINTELLA. 


\section{0 - DIRETOR: CARLOS FRANCISCO TEODORO MACHADO RIBEIRO DE LESSA}

PRESIDENTE: LUIS INÁCIO LULA DA SILVA

PERÍODO DA HISTÓRIA: DEMOCRACIA

GESTÃO: JANEIRO 2003 - NOVEMBRO 2004

LOCAL E DATA DE NASCIMENTO: 30/06/1936 RIO DE JANEIRO

LOCAL E DATA DE MORTE:

FORMAÇÃO/PROFISSÃO:

ESTUDOU NO TRADICIONAL COLÉGIO PADRE ANTONIO VIEIRA

1959 -GRADUADO EM CIÊNCIAS ECONÔMICAS NA ANTIGA UNIVERSIDADE DO BRASIL, HOJE UFRJ

1960 - INICIOU O CURSO DE MESTRADO EM ANÁLISE EONÔMICA NO CONSELHO NACIONAL DE ECONOMIA.

1961 - LECIONOU NO CURSO DE FORMAÇÃO DE DIPLOMATAS DO INSTITUTO RIO BRANCO, DO MINISTÉRIO DAS RELAÇÕES EXTERIORES.

1964 - CONCLUIU MESTRADO

1980 - DOUTOR PELO IFCH/UNICAMP

CARREIRA: 1962 - TORNOU-SE PROFESSOR DOS CURSOS INTENSIVOS DE TREINAMENTO DOS PROBLEMAS DE DESENVOLVIMENTO ECONÔMICO DA CEPAL/ORGANIZAÇÃO DAS NAÇÕES UNIDAS (ONU), MINISTRANDO AULAS NO RIO DE JANEIRO, EM MINAS GERAIS, NO CEARÁ E NO RIO GRANDE DO SUL.

- LECIONOU NA SUPERINTENDÊNCIA DO DESENVOLVIMENTO DO NORDESTE (SUDENE), OFERECENDO CURSOS EM RECIFE E SALVADOR.

1964 - CONCLUIU O MESTRADO E ENCERROU SUA PARTICIPAÇÃO COMO DOCENTE DO INSTITUTO RIO BRANCO E DA CEPAL/ONU.

1965-1968 - LECIONOU NO INSTITUTO LATINOAMERICANO Y DEL CARIBE DE PLANIFICACIÓN ECONÔMICA Y SOCIAL (ILPES/ONU), FICANDO BASEADO NO CHILE, NICARÁGUA E EL SALVADOR

- INGRESSOU NO CENTRO INTERAMERICANO DE CAPACITAÇÃO EM ADMINISTRAÇÃO PÚBLICA, ATUANDO EM BUENOS AIRES E CARACAS

1966-1969 - PROFESSOR DO INSTITUTO PARA INTEGRAÇÃO DA AMÉRICA LATINA (INTAL), FINANCIADO PELO BANCO INTERAMERICANO DE DESENVOLVIMENTO (BID), LOCALIZADO NA CAPITAL ARGENTINA

1967 - LECIONOU NO CURSO DE PÓS-GRADUADOS DA ESCOLA LATINO-AMERICANA DO INSTITUTO DE ECONOMIA DA UNIVERSIDADE DO CHILE, EM SANTIAGO.

1969-1973 - PROFESSOR DO INSTITUTO DE ESTUDOS EM ADMINISTRAÇÃO PÚBLICA DA FUNDAÇÃO GETÚLIO VARGAS (IEAP/FGV), NO RIO DE JANEIRO, NO QUAL MINISTROU AS DISCIPLINAS DE INTRODUÇÃO À ECONOMIA POLÍTICA E INTRODUÇÃO AO PLANEJAMENTO NA ECONOMIA BRASILEIRA

1973-1979 - DIRETOR DA FIRMA CLAN S/A, CONSULTORIA E PLANEJAMENTO DANDO PROSSEGUIMENTO À SUA CARREIRA ACADÊMCIA

1974-1994 - PROFESSOR TITULAR DE POLÍTICA ECONÔMICA DO INSTITUTO DE FILOSOFIA E CIÊNCIAS HUMANAS (IFCH) (UNICAMP), ONDE LECIONOU AS DISCIPLINAS TEORIA ECONÔMICA II, POLÍTICA ECONÔMICA, ECONOMIA BRASIL

1978, - FOI APROVADO EM CONCURSO PARA PROFESSOR TITULAR DE ECONOMIA BRASILEIRA DO INSTITUTO DE ECONOMIA (IE) DA UFRJ E SE TORNOU TAMBÉM PROFESSOR DA PÓS-GRADUAÇÃO DO INSTITUTO DE ECONOMIA INDUSTRIAL IEI/UFRJ, LECIONANDO A DISCIPLINA INDUSTRIALIZAÇÃO BRASILEIRA, NA PÓS-GRADUAÇÃO, E AS DISCIPLINAS ECONOMIA BRASILEIRA II E ECONOMIA E 
SOCIEDADE NO RIO DE JANEIRO, NA GRADUAÇÃO. TAMBÉM NESSE PERÍODO FOI CONSULTOR DO CENTRO DE ESTUDOS E PESQUISAS DA FINEP E CONSULTOR DA FUNDAÇÃO PARA O DESENVOLVIMENTO DA ADMINISTRAÇÃO PÚBLICA DO GOVERNO DE SÃO PAULO/ FUNDAP, ATIVIDADE QUE DESEMPENHARIA ATÉ 1983.

2002 - CONCORREU A UMA VAGA NA CÂMARA DOS DEPUTADOS PELO PMDB DO RIO DE JANEIRO NO PLEITO DE NOVEMBRO,AGREGANDO EM SUA CAMPANHA GRANDE NÚMERO DE INTELECTUAIS E EXALUNOS, OBTEVE CERCA DE 15.000 VOTOS, TOTAL INSUFICIENTE PARA GARANTIR SUA ELEIÇÃO.

- EXERCEU SEU PRIMEIRO CARGO PÚBLICO DURANTE O GOVERNO DE JOSÉ SARNEY (1985-1990). COM A ASCENSÃO DO GRUPO DE ECONOMISTAS QUE APOIAVA O "DR. ULISSES"

1985 - DIRETORDO FUNDO DE INVESTIMENTO SOCIAL (FINSOCIAL) NO BANCO NACIONAL DE DESENVOLVIMENTO ECONÔMICO E SOCIAL. PERMANECEU NO CARGO ATÉ 1988. NESSE PERÍODO, FOI TAMBÉM CONSELHEIRO DO CONSELHO SUPERIOR DE PREVIDÊNCIA SOCIAL ENTRE 1986 E 1989.

1986 - VOLTA A VIDA ACADÊMICA

1988 - DIRETOR DO IFCH/UNICAMP

1992-1994 - PROFESSOR VISITANTE DA UNIVERSIDADE ESTADUAL DO RIO DE JANEIRO (UERJ) OCUPANDO O CARGO DE COORDENADOR DO CENTRO DE ESTUDOS E PESQUISAS (CEP/RIO)

1993-1995 - NA PRIMEIRA GESTÃO DE CESAR MAIA NA PREFEITURA CARIOCA, FOI CONVIDADO PARA OCUPAR O CARGO DE DIRETOR EXECUTIVO DO PLANO ESTRATÉGICO DA CIDADE DO RIO DE JANEIRO, APRIMORANDO SEUS CONHECIMENTOS SOBRE A CAPITAL FLUMINENSE.

1996-1997 EXERCEU FUNÇÕES ADMINISTRATIVAS NO MUNDO ACADÊMICO, OCUPANDO A DIREÇÃO DO INSTITUTO DE ECONOMIA DA UFRJ. NESSE MESMO PERÍODO, ATUOU TAMBÉM CARGOS NA INICIATIVA PRIVADA, SENDO DIRETOR-PRESIDENTE DA DETEN S/A - DETERGENTES DO NORDESTE

1999 - PRESIDENTE DO INSTITUTO VIRTUAL DE ECONOMIA E LOGÍSTICA DO RIO DE JANEIRO.

1998-2002 - DECANO DO CENTRO DE CIÊNCIAS JURÍDICAS E ECONÔMICAS DA UFRJ

2001 - PROFESSOR TITULAR VISITANTE DA COPPE/UFRJ

2002 - REITOR DA UNIVERSIDADE FEDERAL DO RIO DE JANEIRO, OBTENDO UMA VOTAÇÃO CONSAGRADORA: OBTEVE 85\% DOS VOTOS DOS 13.453 ELEITORES, ENTRE PROFESSORES, FUNCIONÁRIOS E ALUNOS. NO ENTANTO, PERMANECEU MENOS DE UM ANO À FRENTE DA UFRJ.

2003 - ACEITOU O CONVITE DO RECÉM-EMPOSSADO PRESIDENTE DA REPÚBLICA LUÍS INÁCIO LULA DA SILVA PT, PARA OCUPAR A PRESIDÊNCIA DO BNDES , A DECISÃO FOI TOMADA APÓS UMA LONGA REUNIÃO COM OS MEMBROS DO CONSELHO UNIVERSITÁRIO DA UFRJ. FICOU ACERTADO QUE LESSA SE AFASTARIA POR 90 DIAS DA REITORIA, FICANDO A UNIVERSIDADE ENTÃO SOB O COMANDO DO VICEREITOR DA ENTIDADE, SÉRGIO FRACALANZA, E DEPOIS SERIAM REALIZADAS NOVAS ELEIÇÕES.

2004 - RETORNOU PARA O ENSINO SUPERIOR, VOLTANDO A LECIONAR NA COPPE-UFRJ COMO PROFESSOR VISITANTE

- FORA DO BRASIL, ALÉM DA SUA PASSAGEM PELA ESCOLATINA, MINISTRANDO CURSO COMO PROFESSOR CONVIDADO, CARLOS LESSA LECIONOU NA UNIVERSIDAD NACIONAL DE VENEZUELA, NA UNIVERSIDAD NACIONAL AUTÓNOMA DE MÉXICO E NA UNIVERSIDAD COMPLUTENSE DE MADRI E EM MAIS QUATRO UNIVERSIDADES ESPANHOLAS.

FILIAÇÃO PARTIDÁRIA: PMDB - PSB - PSOL

PARENTESCO: FILHO DO MÉDICO E BIBLIÓFILO CLADO RIBEIRO DE LESSA E DE AMÉLIA MACHADO RIBEIRO DE LESSA.FOI PRÉ-CANDIDATO A PREFEITO DA CIDADE PELO PSB EM 2008, DESISTINDO NO DECORRER DO PROCESSO ELEITORAL. MANTÉM INÚMEROS EMPREENDIMENTOS NO CORREDOR CULTURAL DO CENTRO DO RIO. CASOU-SE COM MARTA MARIA HUE RIBEIRO DE LESSA, COM QUEM TEVE TRÊS FILHOS. 
31 - DIRETOR: GUIDO MANTEGA

PRESIDENTE: LUIS INÁCIO LULA DA SILVA

PERÍODO DA HISTÓRIA: DEMOCRACIA

GESTÃO: NOVEMBRO 2004 - MARÇO 2006

LOCAL E DATA DE NASCIMENTO: 07/04/1949 - GÊNOVA - ITÁLIA

LOCAL E DATA DE MORTE:

FORMAÇÃO/PROFISSÃO:1972 ECONOMIA PELA FACULDADE DE ECONOMIA E ADMINISTRAÇÃO E, NESSE MESMO ANO, EM CIÊNCIAS SOCIAIS PELA FACULDADE DE FILOSOFIA, LETRAS E CIÊNCIAS HUMANAS, AMBAS DA UNIVERSIDADE DE SÃO PAULO (USP)

1976 MANTEGA APRESENTOU, PELO CENTRO BRASILEIRO DE ANÁLISE E PLANEJAMENTO (CEBRAP), NA 28․ REUNIÃO DA SOCIEDADE BRASILEIRA PARA O PROGRESSO DA CIÊNCIA, REALIZADA EM BRASÍLIA, O SEU PRIMEIRO TEXTO ACADÊMICO DE DESTAQUE, EXPANSÃO E CRISE NA ECONOMIA BRASILEIRA: $O$ PAPEL DO CAPITAL ESTRANGEIRO.

1977 - FEZ UM CURSO DE ESPECIALIZAÇÃO EM SOCIOLOGIA NO INSTITUTE OF DEVELOPMENT STUDIES (IDS) DA UNIVERSIDADE DE SUSSEX, NA INGLATERRA

1980 - FILIOU-SE AO PARTIDO DOS TRABALHADORES (PT), AGREMIAÇÃO POLÍTICA FUNDADA NESSE ANO COMO UMA NOVA OPÇÃO PARTIDÁRIA SOCIALISTA DEMOCRÁTICA, REUNINDO MILITANTES DO MOVIMENTO SINDICAL DO ABC PAULISTA E DOS MOVIMENTOS SOCIAIS, INTELECTUAIS E MILITANTES CATÓLICOS LIGADOS À TEOLOGIA DA LIBERTAÇÃO, ENTRE OUTROS.EM 1981 TORNOU-SE PROFESSOR DE ECONOMIA DA ESCOLA DE ADMINISTRAÇÃO DE EMPRESAS DA FUNDAÇÃO GETÚLIO VARGAS DE SÃO PAULO.

- POUCO DEPOIS DE CONCLUIR O CURSO DE MESTRADO, APRESENTANDO A DISSERTAÇÃO RAÍZES E FORMAÇÃO DA ECONOMIA BRASILEIRA, FOI CONVIDADO POR FERNANDO HENRIQUE CARDOSO, UM DOS EXPOENTES DO CEBRAP, A FAZER O DOUTORADO EM SOCIOLOGIA DO DESENVOLVIMENTO NA FACULDADE DE FILOSOFIA, LETRAS E CIÊNCIAS HUMANAS DA USP SOB SUA ORIENTAÇÃO.

1982 - DEFENDE SUA TESE - A ECONOMIA POLÍTICA BRASILEIRA, OBTENDO NOTA MÁXIMA E RECOMENDAÇÃO PARA PUBLICAÇÃO. ALÉM DE CARDOSO PARTICIPARAM DA BANCA EXAMINADORA O PAUL SINGER, LUÍS CARLOS BRESSER PEREIRA E BRASÍLIO SALLUM JR.

CARREIRA:

1982, MANTEGA FOI CONVIDADO PARA LECIONAR ECONOMIA NO CURSO DE MESTRADO E DOUTORADO DA PONTIFÍCIA UNIVERSIDADE CATÓLICA DE SÃO PAULO (PUC-SP). PERMANECERIA NA PUC-SP ATÉ 1987, EXERCENDO NO PERÍODO COMPREENDIDO ENTRE 1984 E 1987 O CARGO DE VICE-REITOR ADJUNTO. 
1988 - PARTICIPOU DIRETAMENTE DA CAMPANHA VITORIOSA DE LUÍSA ERUNDINA PARA A PREFEITURA DE SÃO PAULO. COM A ELEIÇÃO DA PRIMEIRA MULHER PARA A GESTÃO DO MAIOR MUNICÍPIO DO PAÍS, MANTEGA FOI CONVIDADO

1989-1992 - CHEFE DE GABINETE DA SECRETARIA MUNICIPAL DE PLANEJAMENTO DE SÃO PAULO, CUJO TITULAR ERA O PROFESSOR PAULO SINGER. POUCO DEPOIS, ASSUMIU O CARGO DE DIRETOR DE ORÇAMENTO. PERMANECERIA NO GOVERNO PAULISTANO, NO FINAL DA GESTÃO DE ERUNDINA. E SUA PRIMEIRA EXPERIÊNCIA NA VIDA PÚBLICA ISSO APROXIMOU DA PRINCIPAL LIDERANÇA DO PT, O OPERÁRIO LUÍS INÁCIO LULA DA SILVA.

- GUIDO MANTEGA INTEGROU A COORDENAÇÃO DO PROGRAMA ECONÔMICO DO PT NA CAMPANHA DE LULA À PRESIDÊNCIA DA REPÚBLICA AO LONGO DE 1989. O CANDIDATO PETISTA OBTEVE EXPRESSIVA VOTAÇÃO NO PRIMEIRO TURNO DAS ELEIÇÕES, REALIZADO EM NOVEMBRO, MAS FOI DERROTADO, NO SEGUNDO TURNO FINAL, EM DEZEMBRO, PELO EX-GOVERNADOR DE ALAGOAS, FERNANDO COLLOR DE MELLO.

1993 - ASSESSOR ECONÔMICO DE LUÍS INÁCIO LULA DA SILVA.

1994 - UM DOS COORDENADORES DO PROGRAMA ECONÔMICO DO PT E EM CONJUNTO COM ALOIZIO MERCADANTE, JORGE MATOSO E OUTROS EXPOENTES DO PARTIDO CRITICARAM O PLANO REAL, AVALIANDO MAL OS DIVIDENDOS POLÍTICOS QUE TRARIA. LULA FOI DERROTADO NO PLEITO AINDA NO PRIMEIRO TURNO POR FERNANDO HENRIQUE CARDOSO, CANDIDATO DO PARTIDO DA SOCIAL DEMOCRACIA BRASILEIRA (PSDB), EM COLIGAÇÃO COM O PARTIDO DA FRENTE LIBERAL (PFL) QUE OCUPOU A VICE-PRESIDÊNCIA COM MARCO MACIEL. NA ESTEIRA DO PLANO REAL E DA ESTABILIDADE MONETÁRIA, FERNANDO HENRIQUE ELEGEU-SE COM MAIS DE 54\% DOS VOTOS VÁLIDOS. LULA, APESAR DE NAS PESQUISAS APARECER DURANTE UM BOM TEMPO COMO PREFERIDO DOS ELEITORES, OBTEVE POUCO MAIS DE $27 \%$ DOS VOTOS.

1998 - FERNANDO HENRIQUE CARDOSO SERIA NOVAMENTE CANDIDATO, POIS EM 21 DE MAIO DE 1997, EM MEIO A DENÚNCIAS DE COMPRAS DE VOTOS E PROTESTOS, O SENADO APROVOU EM PRIMEIRO TURNO, POR 63 VOTOS A FAVOR E SEIS CONTRA, A EMENDA CONSTITUCIONAL NO. 16 QUE PERMITIU A REELEIÇÃO DO PRESIDENTE DA REPÚBLICA E DE OUTROS CARGOS MAJORITÁRIOS. COM LULA CANDIDATO, MANTEGA NOVAMENTE INTEGROU A COORDENAÇÃO DO PROGRAMA ECONÔMICO DO PT. FERNANDO HENRIQUE CARDOSO E MARCO MACIEL - LANÇADOS POR UMA COLIGAÇÃO PARTIDÁRIA QUE, NESSA OPORTUNIDADE, INCLUIU, ALÉM DO (PSDB E DO PFL, O PARTIDO DO MOVIMENTO DEMOCRÁTICO BRASILEIRO (PMDB), O PARTIDO TRABALHISTA BRASILEIRO (PTB) E O PARTIDO PROGRESSISTA (PP) REELEGERAM-SE AINDA NO PRIMEIRO TURNO, OBTENDO MAIS DE 53\% DOS VOTOS

2003 - ASSUME O MINISTÉRIO DO PLANEJAMENTO, ORÇAMENTO E GESTÃO, PASTA RESPONSÁVEL PELO GERENCIAMENTO DOS GASTOS PÚBLICOS E TAMBÉM PELA EXECUÇÃO DO ORÇAMENTO E ELABORAÇÃO DO PLANO PLURIANUAL DE INVESTIMENTOS (PPA).

- SUA SAÍDA DO PLANEJAMENTO SE CONCRETIZOU APÓS FORTE DESGASTE QUE O ECONOMISTA CARLOS LESSA, PRESIDENTE DO BANCO NACIONAL DE DESENVOLVIMENTO ECONÔMICO (BNDES), SOFREU. DEPOIS DE ENTRAR EM CONFLITO COM O PRESIDENTE DO BANCO CENTRAL HENRIQUE MEIRELES E COM PALOCCI, EM TORNO DA NECESSIDADE DE REDUÇÃO DA TAXA DE JUROS DE LONGO PRAZO (TJLP), E NÃO RECEBENDO O APOIO DE LUÍS FERNANDO FURLAN, TITULAR DO MINISTÉRIO DO 
DESENVOLVIMENTO, INDÚSTRIA E COMÉRCIO EXTERIOR, AO QUAL O BNDES ESTÁ FORMALMENTE SUBORDINADO

2004-2007 - PRESIDENTE BNDES

2009 - MINISTRO DA FAZENDA E O SINDICATO DOS METALÚRGICOS DO ABC PAULISTA LHE DÁ O PRÊMIO JOÃO FERRADOR, PERSONAGEM SÍMBOLO DO MOVIMENTO SINDICAL NOS ANOS 1980, PELO SEU DESEMPENHO NO ENFRENTAMENTO DA CRISE ECONÔMICA MUNDIAL E PELA DEFESA DOS DIREITOS DOS TRABALHADORES.

FILIAÇÃO PARTIDÁRIA: PT

PARENTESCO: SUA FAMÍLIA VEIO PARA O BRASIL EM 1952, FIXANDO-SE EM SÃO PAULO, ONDE SEU PAI, UM EX-MILITAR DO EXÉRCITO ITALIANO, TORNOU-SE UM PEQUENO EMPRESÁRIO. 
32 - DIRETOR : DEMIAN FIOCCA

PRESIDENTE: LUIS INÁCIO LULA DA SILVA

PERÍODO DA HISTÓRIA: DEMOCRACIA

GESTÃO: MARÇO 2006 - MAIO 2007

LOCAL E DATA DE NASCIMENTO: SÃO PAULO EM 1969

LOCAL E DATA DE MORTE:

FORMAÇÃO/PROFISSÃO: FORMOU-SE EM ECONOMIA PELA UNIVERSIDADE DE SÃO PAULO (USP), INSTITUIÇÃO NA QUAL CONCLUIU O SEU CURSO DE MESTRADO.

CARREIRA:

1992-1994 -PESQUISADOR DO INSTITUTO DE ESTUDOS ECONÔMICOS, SOCIAIS E POLÍTICOS DE SÃO PAULO ENTRE COORDENOU, NO BRASIL, PESQUISA DE CAMPO SOBRE O PROCESSO DE INTEGRAÇÃO REGIONAL DO MERCOSUL, ENCOMENDADA PELO BANCO INTERAMERICANO DE DESENVOLVIMENTOINSTITUTO PARA LA INTEGRACIÓN DE AMÉRICA LATINA Y EL CARIBE (BID-INTAL). AINDA EM 1994, TORNOU-SE ARTICULISTA E EDITORIALISTA DA FOLHA DE S. PAULO, PERMANECENDO LIGADO A ESSE JORNAL ATÉ 1998. NESSE ÓRGÃO DA IMPRENSA PAULISTA, ASSINOU, DURANTE DOIS ANOS, UMA COLUNA DOMINICAL NO "CADERNO DINHEIRO".

1998- 2000 - ECONOMISTA-CHEFE DO BANCO HSBC NO BRASIL, DIRIGIU A ÁREA DE ECONOMIA DESSA INSTITUIÇÃO FINANCEIRA E FOI RESPONSÁVEL PELAS ANÁLISES DE ECONOMIA E DE MERCADOS, BEM COMO PELA PUBLICAÇÃO DOS BOLETINS DE PESQUISA ECONÔMICA DO BANCO.

2000-2003 - FOI ECONOMISTA-CHEFE DO GRUPO ESPANHOL TELEFÓNICA E MEMBRO DO COMITÊ RESPONSÁVEL PELO POSICIONAMENTO FINANCEIRO DO GRUPO NO BRASIL.

- PASSOU TAMBÉm A ASSESSORAR O PRESIDENTE DA TELEFÓNICA EM SUAS CONTRIBUIÇÕES AO CONSELHO DE DESENVOLVIMENTO ECONÔMICO E SOCIAL (CDES), ÓRGÃO CRIADO PELA PRESIDÊNCIA DA REPÚBLICA NO PRIMEIRO MANDATO DO PRESIDENTE LUIS INÁCIO LULA DA SILVA, COM O OBJETIVO DE ESTABELECER O DIÁLOGO ENTRE AS DIVERSAS REPRESENTAÇÕES DA SOCIEDADE CIVIL A FIM DE E DISCUTIR AS POLÍTICAS PÚBLICAS E PROPOR AS MEDIDAS NECESSÁRIAS PARA ESTIMULAR O CRESCIMENTO DO PAÍS.

- FOI CONVIDADO POR GUIDO MANTEGA, SEU EX-PROFESSOR NA USP, A OCUPAR O CARGO DE SECRETÁRIO DE ASSUNTOS INTERNACIONAIS DO MINISTÉRIO DO PLANEJAMENTO, ORÇAMENTO E GESTÃO.

2004 - PASSOU A CHEFIAR A ASSESSORIA ECONÔMICA DA PASTA. COM A IDA DE MANTEGA PARA A PRESIDÊNCIA DO BANCO NACIONAL DE DESENVOLVIMENTO ECONÔMICO E SOCIAL (BNDES), FIOCCA TORNOU-SE VICE-PRESIDENTE DA INSTITUIÇÃO E ENTRE OUTRAS ATRIBUIÇÕES, FOI RESPONSÁVEL PELAS ÁREAS DE CONTROLE E TECNOLOGIA DA INFORMAÇÃO, INFRA-ESTRUTURA E INSUMOS BÁSICOS. 
2006-2007 - PRESIDIU O BNDES NO LUGAR DE MANTEGA, QUE FORA GUINDADO AO CARGO DE MINISTRO DA FAZENDA. EM PARALELO, TORNOU-SE MEMBRO DO CONSELHO MONETÁRIO NACIONAL, GOVERNADOR ALTERNO DO BRASIL NO BID, DIRETOR DA CORPORAÇÃO ANDINA DE FOMENTO E MEMBRO DO CONSELHO DE ADMINISTRAÇÃO DA COMPANHIA HIDRELÉTRICA DO SÃO FRANCISCO (CHESF)

2007- ASSUMIU, UMA DIRETORIA CRIADA ESPECIFICAMENTE PARA ELE NA COMPANHIA VALE DO RIO DOCE (CVRD), A SEGUNDA MAIOR MINERADORA DO MUNDO: A DE TECNOLOGIA E GESTÃO CORPORATIVA

- 2005-2007-REPRESENTANTE DO BNDES NO CONSELHO DE ADMINISTRAÇÃO DA VALEPAR, HOLDING QUE REÚNE O BLOCO DE CONTROLE DA COMPANHIA VALE DO RIO DOCE (CVRD), RESPONSÁVEL PELAS DECISÕES ESTRATÉGICAS DA EMPRESA

2008 - DIRETOR-EXECUTIVO DE GESTÃO E SUSTENTABILIDADE DA CVRD.

2009 - PRESIDENTE DA NOSSA CAIXA, INSTITUIÇÃO BANCÁRIA QUE PERTENCIA AO GOVERNO DO ESTADO DE SÃO PAULO E PASSOU A SER CONTROLADO PELO BANCO DO BRASIL EM MARÇO DAQUELE ANO.

FILIAÇÃO PARTIDÁRIA:

PARENTESCO: 
PRESIDENTE: DILMA ROUSSEF

PERÍODO DA HISTÓRIA: DEMOCRACIA

GESTÃO: $\quad$ MAIO 2007 - JANEIRO 2010

LOCAL E DATA DE NASCIMENTO: 29/09/1946 - RECIFE/PE

LOCAL E DATA DE MORTE:

FORMAÇÃO/PROFISSÃO

1962-1964 - FEZ O CURSO MÉDIO NO COLÉGIO SÃO LUIS, EM RECIFE

1967 - RECEBEU O PRÊMIO GASTÃO VIDIGAL DESTINADO AO MELHOR ALUNO EM ECONOMIA DO ESTADO DE SÃO PAULO. DURANTE A GRADUAÇÃO, MILITOU NO MOVIMENTO ESTUDANTIL PAULISTA, QUE SE OPUNHA AO REGIME MILITAR INSTALADO NO PAÍS EM ABRIL DE 1964.

1968 - INGRESSOU NA UNIVERSIDADE DE SÃO PAULO (USP), POR ONDE SE GRADUOU EM CIÊNCIAS ECONÔMICAS

1970 - CURSOU O MESTRADO EM ECONOMIA PELA (USP).

1974 - FEZ O DOUTORADO, TAMBÉM EM ECONOMIA, PELA UNIVERSIDADE DE CORNELL, NOS ESTADOS UNIDOS, NA QUAL DEFENDEU A TESE THE INTERNATIONALIZATION OF OLIGOPOLY CAPITAL

CARREIRA:

1979 - PROFESSOR VISITANTE DO INSTITUTO DE PESQUISAS ECONÔMICAS DA USP

- COORDENOU O PROGRAMA DE PÓS-GRADUAÇÃO EM ECONOMIA DA UNIVERSIDADE ESTADUAL DE CAMPINAS (UNICAMP), ESTRUTURANDO A ÁREA DE PESQUISA INDUSTRIAL DAQUELE ESTABELECIMENTO DE ENSINO SUPERIOR

1980 - FOI PROFESSOR VISITANTE DA UNIVERSIDADE DO TEXAS, SENDO QUALIFICADO COMO EDWARD L. TINKER PROFESSOR.

EM 1984- 1985 - PRESIDIU O CONSELHO REGIONAL DE ECONOMIA DA SÃO PAULO.

1980 - 1988 - COUTINHO APROXIMOU-SE DA ALA NACIONALISTA E DESENVOLVIMENTISTA DO PARTIDO DO MOVIMENTO DEMOCRÁTICO BRASILEIRO (PMDB), JUNTAMENTE COM OUTROS ECONOMISTAS DE DESTAQUE, ENTRE OS QUAIS CELSO FURTADO, MARIA DA CONCEIÇÃO TAVARES E LUIZ GONZAGA BELUZZO. ESPECIALISTA NA ÁREA INDUSTRIAL, EM 1985, QUANDO O MINISTRO RENATO ARCHER ASSUMIU A PASTA DO RECÉM-CRIADO MINISTÉRIO DA CIÊNCIA E TECNOLOGIA DO GOVERNO JOSÉ SARNEY (1985-1990), LUCIANO COUTINHO FOI CONVIDADO PARA SER SECRETÁRIO GERAL DA PASTA, PARTICIPANDO DE SUA ESTRUTURAÇÃO E DA CONCEPÇÃO DE POLÍTICAS VOLTADAS PARA ÁREAS DE ALTA COMPLEXIDADE, COMO BIOTECNOLOGIA, QUÍMICA FINA, MECÂNICA DE PRECISÃO, NOVOS 
MATERIAIS E INFORMÁTICA. ESSE ÚLTIMO SETOR MOBILIZOU A CÚPULA DO MINISTÉRIO QUE ERA AMPLAMENTE FAVORÁVEL À RESERVA DE MERCADO PARA O AVANÇO DA INDÚSTRIA BRASILEIRA.

- 1986, PROFESSOR TITULAR DO INSTITUTO DE ECONOMIA DA UNICAMP. AO DEIXAR O GOVERNO, INTENSIFICOU SEU TRABALHO DE CONSULTOR, ATUANDO JUNTO AO SERVIÇO BRASILEIRO DE APOIO ÀS MICRO E PEQUENAS EMPRESAS (SEBRAE), DO BANCO DO NORDESTE E DE VÁRIOS GOVERNOS ESTADUAIS. SUA PASSAGEM PELA VIDA PÚBLICA LHE DARIA GRANDE TRÂNSITO E AMPLIARIA SEUS CONHECIMENTOS COM PERSONALIDADES IMPORTANTES DA VIDA PÚBLICA, COMO FOI O CASO DO ATUAL MINISTRO DAS RELAÇÕES EXTERIORES, CELSO AMORIM, QUE ESTAVA NO MINISTÉRIO DA CIÊNCIA E TECNOLOGIA QUANDO COUTINHO FOI SECRETÁRIO GERAL, E TAMBÉM DA INICIATIVA PRIVADA, ONDE MANTEVE RELAÇÕES ESTREITAS COM A CONFEDERAÇÃO NACIONAL DA INDÚSTRIA (CNI).

1990 - RETORNOU À PRESIDÊNCIA DOCONSELHO REGIONAL DE ECONOMIA DE SÃO PAULO

1994 - PROFESSOR VISITANTE DA UNIVERSIDADE DE PARIS XIII E, POSTERIORMENTE, COMO PROFESSOR VISITANTE DO INSTITUTO UNIVERSITARIO DE INVESTIGACIÓN ORTEGA Y GASSET, LIGADO A FUNDAÇÃO ORTEGA Y GASSET EM MADRI, ESPANHA. NESTE MESMO ANO, COORDENOU UM ESTUDO DE GRANDE ENVERGADURA, DENOMINADO "ESTUDO DA COMPETITIVIDADE DA INDÚSTRIA BRASILEIRA", FINANCIADO EM PARTE PELO BANCO NACIONAL DE DESENVOLVIMENTO ECONÔMICO E SOCIAL (BNDES), ARTICULANDO DIVERSAS UNIVERSIDADES E CENTROS DE PESQUISAS BRASILEIROS, E QUASE UMA CENTENA DE ESPECIALISTAS. ESTE ESTUDO, QUE SERIA TRANSFORMADO EM LIVRO COORDENADO POR ELE E POR JOÃO CARLOS FERRAZ, MAPEOU O ESTADO DA ARTE DA INDÚSTRIA BRASILEIRA, AS NECESSIDADES DE INOVAÇÃO E AS CONDIÇÕES DE CONCORRÊNCIA NOS MERCADOS INTERNACIONAIS. 1996 - ALÉM DE EXERCER AS ATIVIDADES DE PROFESSOR E DE CONSULTOR, COUTINHO FOI TAMBÉM APRESENTADOR DO PROGRAMA O BRASIL PENSA, NA TV CULTURA, DE SÃO PAULO, TRANSMITIDO EM REDE PARA O BRASIL E QUE TRATAVA DE ASSUNTOS LIGADOS AO CONHECIMENTO. AINDA NOS ANOS 1990 SE APROXIMOU DO PARTIDO DOS TRABALHADORES (PT), DEVIDO SOBRETUDO ÀS SUAS RELAÇÕES DE AMIZADE COM O HOJE SENADOR PELO PT PAULISTA ALOÍSIO MERCADANTE, DE QUEM FORA PROFESSOR, DO PROFESSOR DA PONTIFÍCIA UNIVERSIDADE DE SÃO PAULO (PUC-SP) MARCO AURÉLIO GARCIA, HOJE ASSESSOR INTERNACIONAL DO PRESIDENTE LUÍS INÁCIO LULA DA SILVA, E DE JORGE MATOSO, COLEGA DA UNICAMP, DEPOIS FEITO PRESIDENTE DA CAIXA. O CRESCIMENTO DA LCA CONSULTORES - SUA FIRMA DE CONSULTORIA ESPECIALIZADA EM INDÚSTRIA, DEFESA DA CONCORRÊNCIA, COMÉRCIO INTERNACIONAL E PERÍCIAS ECONÔMICAS - PERMITIU-LHE CONSTRUIR UMA VASTA CARTEIRA DE CLIENTES, COMPREENDENDO GRANDES GRUPOS EMPRESARIAIS E FINANCEIROS DO PAÍS, ALÉM DE FUNDOS DE PENSÃO E ESCRITÓRIOS DE ADVOCACIA. ESSA EXPERIÊNCIA PROFISSIONAL LEVOU LUCIANO COUTINHO A AMPLIAR OS SEUS CONHECIMENTOS DOS PRINCIPAIS IMPASSES DA ECONOMIA BRASILEIRA.

- COMANDOU A LCA

2007 - ATUAL PRESIDENTE DO BNDES - DEPOIS DO ÓTIMO DESEMPENHO QUE O BNDES ALCANÇOU EM 2007, AO FINAL DE 2008 O BANCO FOI INSTADO A INSTRUMENTALIZAR POLÍTICAS ANTICÍCLICAS QUE O GOVERNO PROMOVEU DEVIDO À CRISE INTERNACIONAL E RECEBEU APORTE EXTRA DE CAPITAL DO TESOURO. APESAR DAS MUITAS CRÍTICAS QUE RECEBEU DOS SEGUIDORES DE POLÍTICAS FISCAIS 
APERTADAS POR APORTAR RECURSOS EM GRANDES EMPRESAS, INCLUSIVE ESTATAIS, E AUXILIAR OUTRAS EM PROCESSO DE FUSÃO, PARA O DESENVOLVIMENTISTA COUTINHO O BRASIL IRIA SE RECUPERAR RAPIDAMENTE DOS EFEITOS DA CRISE ECONÔMICA MUNDIAL E VOLTARIA A CRESCER JÁ NO SEGUNDO SEMESTRE DE 2009. AS PREVISÕES FEITAS PELO PRESIDENTE DO BNDES SE BASEARAM NO FATO DE QUE OS GRANDES PROJETOS DE INVESTIMENTOS DE INFRAESTRUTURA NO PAÍS SEQUER FORAM POSTERGADOS, DESTACANDO QUE OS INVESTIMENTOS NO SETOR DE ENERGIA ESTÃO EM EXPANSÃO E QUE NÃO HÁ POSSIBILIDADE DE REVERSÃO DESSE QUADRO. PREOCUPADO COM A DEMANDA REPRIMIDA NA ÁREA DE INFRAESTRUTURA, COUTINHO DEFENDEU A EXECUÇÃO DO PAC, AFIRMANDO EXISTIR ENORMES GARGALOS QUE PRECISAM SER RESOLVIDOS COM URGÊNCIA PARA QUE O BRASIL VOLTASSE A TER TAXAS MAIS ELEVADAS DE CRESCIMENTO. FILIAÇÃO PARTIDÁRIA: PMDB - PT - PSB

PARENTESCO: FILHO DE AMAURI DOMINGUES COUTINHO E DE ANA GALVÃO. DIVORCIADO, TEM DOIS FILHOS 
PRESIDENTE: INTERINO MICHEL TEMER

PERÍODO DA HISTÓRIA:

GESTÃO: MAIO 2016

LOCAL E DATA DE NASCIMENTO: Rio de Janeiro, 27/12/1956 